\title{
COMPOSIÇÃo FLORÍSTICA DO COMPARTIMENTO ARBÓREO DE CINCO REMANESCENTES FlORESTAIS do MACiÇO do ITATIAIA, Minas Gerais E RIO DE J JNEIRO ${ }^{1}$
}

\author{
Israel Marinho Pereira ${ }^{2}$, Ary Teixeira de Oliveira-Filho ${ }^{3}$, \\ Soraya Alvarenga Botelho ${ }^{3}$, Warley Augusto Caldas Carvalho ${ }^{4}$, \\ Marco Aurélio Leite Fontes ${ }^{3}$, Ivan Schiavini ${ }^{5}$ \& Alexandre Francisco da Silva ${ }^{6}$
}

\begin{abstract}
Resumo
(Composição florística do compartimento arbóreo de cinco remanescentes florestais do maciço do Itatiaia, Minas Gerais e Rio de Janeiro) Para composição de uma lista florística de espécies arbóreas das florestas do maciço do Itatiaia, foram inventariadas cinco áreas de floresta ombrófila montana situadas nos municípios de Bocaina de Minas e Aiuruoca, sul de Minas Gerais, e Resende, sudoeste do Rio de Janeiro. A listagem de espécies resultou de levantamentos florísticos conduzidos nas cinco áreas, acompanhados de levantamentos fitossociológicos em três delas. Para avaliar as variações da composição da flora arbórea da região, foi extraída da literatura uma listagem adicional de espécies arbóreas de uma área de floresta na vertente sul do maciço Itatiaia, no estado do Rio de Janeiro. A amostra da flora arbórea das cinco áreas estudadas no Maciço do Itatiaia foi composta por 450 espécies, 191 gêneros e 69 famílias, muitas das quais são reconhecidas como características de floresta de altitude (acima de $1.000 \mathrm{~m}$ ). A flora arbórea das florestas do maciço do Itatiaia pode ser considerada como uma das de maior riqueza florística entreáreas de floresta ombrófila montana no sudeste do Brasil. Uma análise de agrupamento identificou padrões de similaridade florística entre as seis áreas de floresta do maciço do Itatiaia, que foram relacionados à ocorrência de inundações periódicas em uma área de floresta ombrófila aluvial, a diferenças em exposição de vertentes (continental ou oceânica) entre as cinco áreas de floresta ombrófila montana e ao estágio sucessional inicial de uma destas. A maior similaridade foi obtida entre duas áreas maduras de floresta ombrófila montana da vertente continental, em Aiuruoca e Bocaina de Minas, apesar da distância geográfica entre as duas ser consideravelmente maior que as distâncias entre a última delas e as áreas de floresta aluvial e em estágio inicial de sucessão.
\end{abstract}

Palavras-chave: Flora arbórea, Floresta Montana, Mata Atlântica, Maciço do Itatiaia.

\section{Abstract}

(Species composition of the tree flora of five forest fragments of the Itatiaia Mountain Range, south-east Brazil) Five rain forest areas situated in the Itatiaia Mountain Range, states of Minas Gerais and Rio de Janeiro, SE Brazil, were surveyed in order to produce a checklist of tree species of the regional forests. This checklist resulted from floristic surveys carried out in the five forest fragments, and phytosociological surveys in three of them. An additional checklist produced for a forest area situated on the Itatiaia southern slopes, state of Rio de Janeiro, was extracted from the literature to help assessing the variations in floristic composition. The tree flora sampled in the five studied areas was composed of 450 species, 191 genera and 69 families, many of which are known as characteristic of montane forests (situated above $1,000 \mathrm{~m}$ of altitude). The tree flora of the Itatiaia Range forests may be considered as one of the richest in species among areas of montane rain forest in SE Brazil. A cluster analysis identified patterns of floristic similarity among the six forest areas of the Itatiaia Range which were related to the occurrence of periodic floods in an area of alluvial rain forest, to differences in slope aspect (oceanic or continental) among the five areas of montane rain forest, and to the early sucessional stage of one of these. The highest similarity was obtained between the areas of mature montane rain forest of the continental slope, in Aiuruoca and Bocaina de Minas, although the geographical distance between them was much greater than the distances between the latter and the areas of alluvial forest and early sucessional forest.

Key-words: Tree flora, Montane Forest, Atlantic Forest, Itatiaia Mountain Range.

Artigo recebido em07/2005. Aceito para publicação em 11/2005.

${ }^{1}$ Parte da tese de doutorado do primeiro autor

${ }^{2}$ Doutorando do Programa de Pós-Graduação em Engenharia Florestal, Departamento de Ciências Florestais, Universidade

Federal de Lavras, 37200-000, Lavras, MG, e-mail: pereiraim@hotmail.com

${ }^{3}$ Departamento de Ciências Florestais, Universidade Federal de Lavras, 37200-000, Lavras, MG.

${ }^{4}$ Doutorando do Programa de Pós-Graduação em Biologia Vegetal, Departamento de Botânica, ICB, Universidade Federal de Minas Gerais, 30161-970, Belo Horizonte, MG

${ }^{5}$ Departamento de Biologia, Campus de Umuarama, Universidade Federal de Uberlândia, 38400-902, Uberlândia, MG

${ }^{6}$ Departamento de Botânica, Universidade Federal de Viçosa, 36571-000, Viçosa, MG 


\section{INTRODUÇão}

O Domínio Atlântico da América do Sul, que envolve tipologias vegetacionais de floresta ombrófilae floresta estacional, além de outros ecossistemas associados, cobria originalmente uma extensão de cerca de 100 milhões de hectares, distribuídos por 17 estados brasileiros, correspondentes a cerca de $16 \%$ do território nacional, e por grandes extensões do leste do Paraguai e nordeste da Argentina (GalindoLeal \& Câmara 2003). A Floresta Atlântica tem sido alvo de exploração desde o período colonial, acompanhando os ciclos agrícolas e a demanda pela expansão das áreas cultivadas e, conseqüentemente, resta hoje menos de $8 \%$ desse total e as principais áreas preservadas estão localizadas nos estados de São Paulo, Rio de Janeiro, Minas Gerais e Espírito Santo (Câmara 2003). Segundo Viana \& Tabanez (1996), a Floresta Atlântica é o ecossistema tropical em estado mais crítico de degradação em todo mundo. Atualmente, a maioria dos seus remanescentes está representada apenas por fragmentos de formações florestais secundárias. Os poucos núcleos que ainda podem ser caracterizados como florestas primárias estão concentrados em áreas de altitude elevada e acesso difícil (Câmara 2003). Além disso, esta reduzida porção da floresta original encontrase ainda na forma de pequenos fragmentos, a grande maioria com menos de 10 ha (Almeida 1996; Collinge 1996). Somam-se ainda os impactos ambientais proporcionados pela degradação sob a forma de erosão do solo, perda de diversidade biológica, invasão de espécies exóticas e degradação de bacias hidrográficas, com a resultante diminuição da qualidade e disponibilidade de água potável (Galindo-Leal et al. 2003).

Além das pronunciadas variações fisionômicas causadas pela heterogeneidade da distribuição de chuvas, as florestas do Domínio Atlântico também apresentam marcantes variações fisionômicas e florísticas vinculadas à altitude (Oliveira-Filho \& Fontes 2000). As florestas de altitude ou montanas do Domínio Atlântico ocorrem no alto dos planaltos ou serras e podem atingir até 2.200 m s.n.m., com variações que respeitam as diferentes faixas de altitude (França \& Stehmann 2004). A despeito da proteção conferida historicamente pela dificuldade de acesso, as ameaças às florestas montanas são particularmente sérias quando se considera que ocupavam uma área proporcionalmente menor que a as florestas de altitude mais baixa e que elas abrigam uma flora muito peculiar. O papel da altitude na composição florística e na estrutura das florestas tropicais tem sido demonstrado por vários autores (Proctor et al. 1988; Gentry 1995; Pendry \& Proctor 1996; Lieberman et al. 1995, 1996; Moreno et al. 2003; Oliveira Filho et al. 2004; França \& Stehmann 2004; Carvalho et al. 2005). Ao longo de um gradiente altitudinal variam concomitantemente muitos fatores do complexo ambiental, tais como temperatura, precipitação pluviométrica, umidade, velocidade dos ventos e outros. Em articulação com estas variações, fisionomias e estruturas florestais diversas se sucedem montanha acima, diferenciando-se comumente a curtas distâncias (Whitmore 1990), muito embora as causas desta zonação altitudinal ainda não sejam totalmente conhecidas (Webster 1995).

As florestas montanas da Região Neotropical estão entre as mais desconhecidas e também encontram-se entre as mais ameaçadas de todas as vegetações florestais dos trópicos (Gentry 1995). Além disso, as florestas montanas que abrigam nascentes de cursos d'água são de fundamental importância para a manutenção da qualidade e quantidade da água e por proporcionarem abrigo e alimento para a fauna regional (Oliveira Filho et al. 2004). Na Região Sudeste do Brasil, grande parte das florestas montanas encontrase situada em altitudes elevadas do complexo montanhoso que inclui as Serras da Mantiqueira e do Mar. Os estudos de descrições florísticas, estruturais e ecológicas de florestas situadas acima de $1.000 \mathrm{~m}$ de altitude no sudeste do Brasil estão em sua fase inicial (Baitello \& Aguiar 1982; Meira Neto et 
al. 1989; Robim et al. 1990; Baitello et al. 1992; Oliveira-Filho \& Machado 1993; Lima \& Guedes-Bruni 1994; Fontes 1997; Castro 2001; Fernandes 2003; Oliveira Filho et al. 2004; Dalanesi et al. 2004; França \& Stehmann 2004; Carvalho et al. 2005).

Situado no eixo Rio-São Paulo, o maciço do Itatiaia, que é parte da Serra da Mantiqueira, vem sofrendo grandes pressões antrópicas desde os tempos coloniais. Por exemplo, a paisagem da vertente interior que aloja as nascentes do rio Grande, em Minas Gerais, mostra na atual pobreza da cobertura florestal o resultado do desflorestamento indiscriminado ocorrido durante o século passado para atender as necessidades madeireiras do eixo Rio-São Paulo, sobretudo a demanda criada durante a instalação da Companhia Siderúrgica Nacional (CSN) em Volta Redonda (Carvalho et al. 2005). Uma considerável amostra das florestas da região foi, no entanto, conservada no Parque Nacional de Itatiaia, o primeiro a ser criado no Brasil, em 1937. No entanto, ainda hoje este Parque sofre pressões antrópicas sérias, como a extração ilegal de palmito.

As florestas da vertente interior do maciço do Itatiaia são ainda muito pouco conhecidas, o quetornaimportantea redização de trabal hos que inventariem a flora dos remanescentesflorestais daregião, incluindo as variações associadas ao histórico de intervenção humana, que resultou nos dife rentes estágios sucessionais. Neste contexto, análises comparativas entre remanescentes permitem uma avaliação da heterogeneidade daflora, do nível desimilaridade entreáreas congêneres e os possíveis fatores associados aos padrões de variação (MeiraNeto et al. 1989; Oliveira-Filho \& Machado 1993; Oliveira-Filho et al. 1994). Tais informações e análises são de fundamental importância para subsidiar iniciativas de conservação ou recuperação ambiental na região. Desta forma, o presente trabalho tem como objetivo descrever e analisar a composição florística de cinco remanescentes de floresta ombrófila da região do maciço do Itatiaia com o propósito final de proporcionar subsídio para ações visando à proteção e recuperação de áreas nessa região.

\section{Material e Métodos}

\section{Caracterização e localização das áreas}

As vertentes continentais do maciço do Itatiaia alojam as nascentes do rio Grande que, após se juntar ao rio Paranaíba, no Triângulo Mineiro, forma o rio Paraná, constituindo assim o eixo da segunda maior bacia hidrográfica da América do Sul. O maciço abriga ainda as nascentes de importantes afluentes do rio Grande, como o Aiuruoca e o Verde, além das nascentes do rio Preto que serve de limite entre os estados de Minas Gerais e Rio de Janeiro naquela região. O clima da região é do tipo Cfa de Köppen (úmido subtropical). Dados de temperatura e precipitação são fornecidos na Tabela 1 para Bocaina de Minas, baseados em Carvalho et al. (2005), Aiuruoca e Visconde de Mauá, baseados em (http:// www.inmet.gov.br /climatologia, 2004) e Itatiaia, baseados em Guedes-Bruni (1998).

Foram estudadas na região do maciço do Itatiaia cinco áreas remanescentes de floresta ombrófila situadas nos municípios de Aiuruoca e Bocaina de Minas, no estado de Minas Gerais, e de Resende (distrito de Visconde de Mauá), no estado do Rio de Janeiro (Tabela 1). As áreas são identificadas como Bmi-1, Bmi-2 e Bmi-3 = Bocaina de Minas 1, 2 e 3; Aiu = Aiuruoca $;$ e Vma = Visconde de Mauá. Uma sexta área, Itt = Itatiaia, inventariada por Guedes-Bruni (1998) na vertente fluminense do Parque Nacional do Itatiaia, foi incluída com o propósito de incrementar as análises comparativas, mas sua listagem não é reproduzida aqui. A situação geográfica das seis áreas é indicada na Figura 1. De acordo com o sistema do IBGE (Veloso et al. 1991), a vegetação se classifica como floresta ombrófila mista montana, no caso de Vma, floresta ombrófila densa aluvial, no caso de Bmi-1, e como floresta ombrófila densa montana, nos demais casos, inclusive Itt. Na classificação de Oliveira-Filho \& Fontes (2000), 


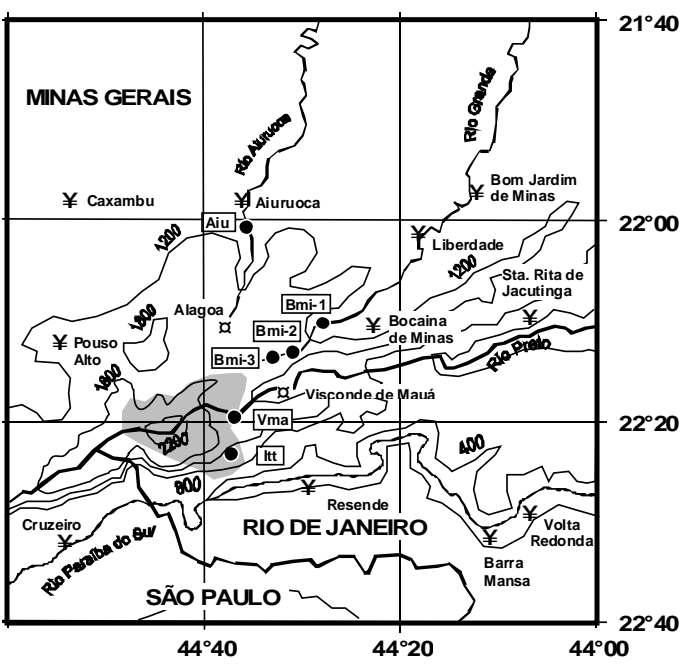

Figura 1 - Localização geográfica dos seis fragmentos de floresta ombrófila montana da região do maciço do Itatiaia utilizados nas análises florísticas (1). A área do Parque Nacional de Itatiaia é indicda em cinza. Curvas hipsométricas em metros de altitude. Bmi-1/2/3 = Bocaina de Minas 1/2/3, Aiu = Aiuruoca; $\operatorname{Vma}=$ Visconde de Mauá; Itt = Itatiaia.

utilizada no presente estudo (Tabela 1), Bmi-1 se classifica como floresta ombrófila aluvial, Vma como floresta ombrófila mista alto-montana, Bmi2 eBmi-3 como floresta ombrófila alto-montana, e Itt e Aiu como floresta ombrófila baixomontana. Descrições de cada remanescente florestal são fornecidas abaixo.

Bmi-1 (Bocaina de Minas 1) é um remanescente florestal de aproximadamente 3 ha situado nas margens do rio Grande, a cerca de $15 \mathrm{~km}$ de sua nascente principal, nas coordenadas $22^{\circ} 10^{\prime}$ sul e $44^{\circ} 28^{\prime}$ oeste e a uma altitude que varia pouco, em torno de $1.135 \mathrm{~m}$. O remanescente reveste ambas as margens do rio Grande e está totalmente inserido em um leito aluvial sujeito a períodos de alagamento. As bordas são abruptas nos limites com pastagens e estradas circunvizinhas e, segundo relatos de habitantes locais, encontra-se em regeneração desde corte raso sofrido há cerca de 50 anos.

Bmi-2 (Bocaina de Minas 2) é um remanescente florestal de cerca de 10 ha, conhecido localmente como Mata da Cachoeira do Rio Grande, que está localizado a cerca de $10 \mathrm{~km}$ a jusante da nascente principal do rio Grande, nas coordenadas $22^{\circ} 13^{\prime}$ sul e $44^{\circ} 32^{\prime}$ oeste. A floresta reveste uma encosta íngreme adjacente à margem esquerda rio Grande e as altitudes em seu interior variam de 1.210 a $1.360 \mathrm{~m}$. A bordas do remanescente são abruptas nos limites com pastagens circunvizinhas. De acordo com informações dos locais, a Mata da Cachoeira é o único remanescente florestal às margens do rio Grande que não sofreu corte raso, pelo menos nos últimos 80 anos. No entanto, a floresta tem sofrido impactos de obras de canalização de água, construção de cercas limítrofes e uso pelo gado. Uma descrição detalhada desta área é fornecida por Carvalho et al. (2005).

Bmi-3 (Bocaina de Minas 3) é um remanescente florestal de aproximadamente 15 ha localizado às margens do rio Grande, a cerca de $5 \mathrm{~km}$ a jusante de sua nascente principal, nas coordenadas $22^{\circ} 14^{\prime}$ sul e $44^{\circ} 34^{\prime}$ oeste. A floresta reveste uma encosta que flanqueia a margem esquerda do rio Grande, com altitudes variando entre 1.400 e $1.480 \mathrm{~m}$. A vegetação encontra-se em estágio inicial de sucessão ecológica, tendo sofrido corte raso há cerca de 40 anos e repetidos cortes nas duas décadas seguintes. As bordas são abruptas nos limites com pastagens circunvizinhas e uma estrada.

Vma (Visconde de Mauá). Esta área foi, na verdade, composta por três remanescentes florestais situados muito próximos uns dos outros (entre 100 e 170 m de distância), nas coordenadas $22^{\circ} 20^{\prime}$ sul e $44^{\circ} 36^{\prime}$ oeste, sendo que dois deles (com áreas de 5 e 7 ha) estão localizados no distrito de Visconde de Mauá, município de Resende (RJ), e o outro ( $8 \mathrm{ha}$ ) no distrito de Mirantão, município de Bocaina de Minas (MG). Os remanescentes estão situados no interior do Parque Nacional de Itatiaia, mas próximos aos seus limites com áreas privadas com intensa atividade turística. As altitudes variam entre 1.150 e $1.350 \mathrm{~m}$.

Aiu (Aiuruoca) é um remanescente florestal com cerca de 10 ha localizado às margens do rio Aiuruoca, em áreas particulares a serem afetadas parcialmente pela construção da 'Pequena Central Hidrelétrica de 


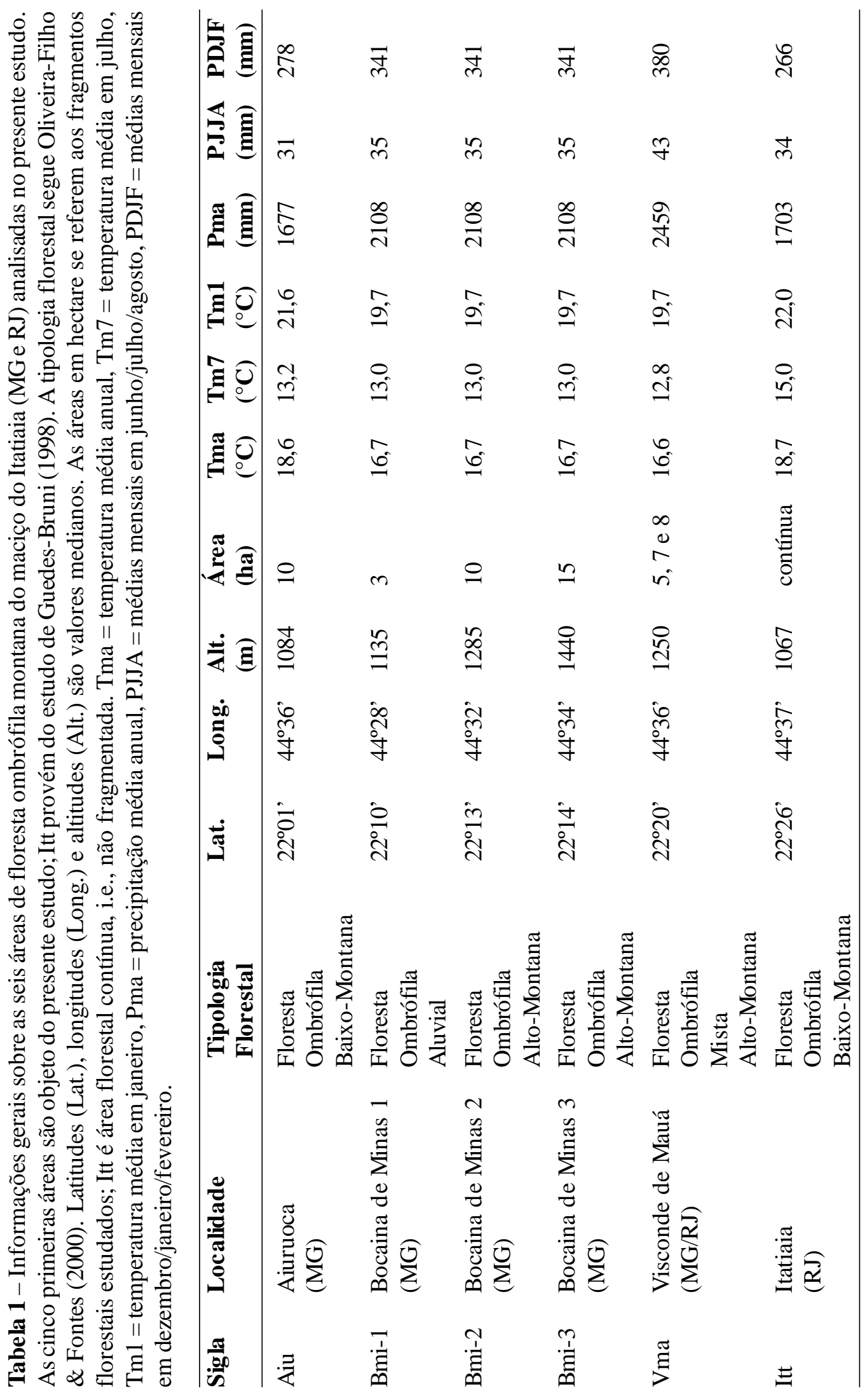

Rodriguésia 57 (1): 103-126. 2006 
Aiuruoca', nas coordenadas $22^{\circ} 01^{\prime}$ sul e $44^{\circ} 36^{\prime}$ oeste. O terreno é muito acidentado, com altitudes variando entre 1.040 e $1.150 \mathrm{~m}$. A floresta se caracteriza por um mosaico de diferentes estágios de sucessão provavelmente como resultado de um variado histórico de intervenções humanas.

\section{Levantamentos florísticos}

As listagens de espécies arbóreas resultaram de levantamentos fitossociológicos e florísticos conduzidos em Bmi-1/2/3 e somente florísticos em Aiu e Vma. Levantamentos fitossociológicos foram conduzidos em 10 parcelas de $10 \times 40 \mathrm{~m}$, nos casos de Bmi-1 e Bmi-3, e em 26 parcelas de $20 \times 20 \mathrm{~m}$ em Bmi2. Nestas três áreas os levantamentos florísticos das espécies arbóreas foram feitos a partir do material testemunho coletado nas unidades amostrais (parcelas), acrescido de coletas realizadas em caminhamentos pelas áreas. Nos casos de Vma e Aiu, os levantamentos florísticos foram realizados por meio de caminhamentos aleatórios no interior dos remanescentes. Em todos levantamentos, foram registrados apenas indivíduos de hábito arbóreo (fuste lenhoso e altura igual ou superior a $3 \mathrm{~m}$ ). O material botânico testemunho foi herborizado e depositado no herbário da Universidade Federal de Lavras (Herbário ESAL). As identificações foram feitas com auxílio de literatura especializadae consultas a especialistas e às coleções dos Herbários ESAL, BHCB (Universidade Federal de Minas Gerais), SP (Instituto de Botânica de São Paulo), RB (Instituto de Pesquisas Jardim Botânico do Rio de Janeiro) e UEC (Universidade Estadual de Campinas). As espécies foram classificadas nas famílias reconhecidas pelo sistema do Angiosperm Phylogeny Group II (APG 2003).

\section{Análises florísticas}

Para a realização das análises florísticas, foi preparado um banco de dados contendo a relação de espécies das cinco áreas do presente estudo mais a área Itt, inventariada por GuedesBruni (1998). Ao final, o banco de dados continha dados binários de presença ou ausência de 503 espécies arbóreas em seis áreas. Foi realizada uma análise de agrupamento das seis áreas baseada na composição de sua flora arbórea com uso do o programa PC-Ord versão 4,0 (McCune \& Mefford 1999). A medida de similaridade florística empregada na análise de agrupamento foi o índice de Jaccard por ser uma medida de simples compreensão, definida pela proporção de espécies em comum (Brower \& Zar 1984). O método de agrupamento foi o das médias não ponderadas (UPGMA), por ser o mais difundido em análises de vegetação (Kent \& Coker 1992).

\section{Resultados e Discussão}

\section{Composição e riqueza de espécies}

A relação das 444 espécies arbóreas, 192 gêneros e 68 famílias botânicas registradas nos cinco remanescentes florestais da região do maciço do Itatiaia encontra-se na Tabela 2. Todos os táxons estão identificados até o nível de espécie; sete espécimes de identificação duvidosa foram excluídos. Caso fosse incluída a área Itt, inventariada por Guedes-Bruni (1998), a amostra total da flora arbórea seria composta por 504 espécies, 210 gêneros e 71 famílias. Os estimadores jackknife (Heltsche \& Forrester 1983; Palmer 1991) do número total de espécies paraa flora arbórea calculados a partir da amostra de seis áreas foram de 715,8 (primeira ordem) e 813,6 espécies (segunda ordem). Estes estimadores não paramétricos fazem uma projeção do número total de espécies a partir da heterogeneidade entre amostras, sendo o segundo deles promove uma inflação maior por se basear nas diferenças máximas. Os valores encontrados são mais elevados que o total de registros no conjunto das seis áreas, mas ainda mais elevados que os totais de espécies registrados em cada uma delas, que variaram entre 82 (Bmi-1) e 231 (Aiu) espécies. Estes números sugerem uma elevada riqueza de espécies regional que resulta, em grande parte, de uma grande variação em composição de espécies entre os remanescentes. De fato, $47 \%$ das 444 espécies só foram registradas em apenas uma das cinco áreas. Para confirmar a alta riqueza regional de espécies, vale mencionar que, 
na região do Alto Rio Grande, que é dez vezes maior que a do maciço do Itatiaia, Pereira (2003) registrou um total de 730 espécies arbóreas em 20 remanescentes florestais, e estimadores jackknife de primeira e segunda ordem de 901,8 e 991,5, respectivamente.

A riqueza de espécies registrada nos remanescentes variou muito e a amplitude ( 82 a 231 espécies) registrada nos fragmentos pode ser considerada como indicativa de riqueza intermediária a elevada, no contexto de outros trabalhos realizados em florestas montanas do estado de Minas Gerais, como os realizados em Carrancas (Oliveira Filho et al. 2004), com 218 espécies; Poço Bonito (Dalanesi et al. 2004), com 213; Camanducaia (França \& Stehmann 2004), com 70; Poços de Caldas (Fernandes 2003), com 105; serrado Ibitipoca(Fontes 1997), com 199; serra do Cipó (Meguro et al. 1996), com 229; e serra do Ambrósio (Pirani et al. 1994), com 71. Diversos fatores de difícil controle podem ser relacionados à grande variação da riqueza entre os remanescentes florestais do presente estudo. Entre eles, podem ser citados o tamanho do fragmento ou da área florestal contínua (Itt), a fisionomia vegetacional e o ambiente a ela relacionado, o histórico de perturbações e as variáveis humanas relacionadas ao método e esforço amostral. As áreas que apresentaram as maiores riquezas de espécies; Aiu (228) e Bmi-2 (218), são precisamente as áreas mais maduras de Floresta Ombrófila AltoMontana. Em seguida, Vma, com 190 espécies também é um remanescente de floresta madura, embora de outra fisionomia, Floresta Ombrófila Mista Alto-Montana. No outro extremo, os remanescentes de menor riqueza, Bmi-1 eBmi-3, com 81 e 119 espécies respectivamente, encontramse ambos em estágios iniciais a intermediários de sucessão ecológica. Além disso, Bmi-1 acrescenta a particularidade de ser umafloresta aluvial sujeita a inundações e seu pequeno número de espécies está provavelmente relacionado com as restrições impostas pela saturação hídrica, que normalmente restringe o estabelecimento de muitas espécies da flora regional; notabilizam-se aí, pela abundância, espécies comuns em ambientes ripários alagáveis, como Sebastiania commersoniana, S. brasiliensis, Vitex megapotamica e Inga vulpina (Botrel et al. 2002; Guilherme et al. 2004).

Nas cinco áreas de floresta do presente estudo, as famílias que se destacaram em riqueza de espécies foram Myrtaceae (44), Melastomataceae (45), Fabaceae (34), Lauraceae (32), Euphorbiaceae (19), Asteraceae (18), Rubiaceae (15), Annonaceae (14), Salicaceae (13) e Solanaceae (12). Juntas, estas famílias representaram $57 \%$ das espécies amostradas (Tabela 2). Tais famílias, com exceção de Salicaceae (em Flacourtiaceae na maioria dos trabalhos), também surgem no elenco de maior riqueza de espécies nos levantamentos realizados em outras áreas de floresta montana (ombrófilas, mistas e estacionais) da Região Sudeste, nos estados de São Paulo (Baitello et al. 1992; Grombone et al. 1990; Mantovani 1990; Robim et al. 1990; Rodrigues et al. 1989), Minas Gerais (Oliveira Filho et al. 2004; França \& Stehmann 2004; Fontes 1997) e Rio de Janeiro (Lima \& Guedes-Bruni 1994). De acordo com Fontes (1997), a maioria destas famílias é característica das florestas situadas acima de $1.000 \mathrm{~m}$ de altitude no sudeste do Brasil.

A influência da altitude na diferenciação florística das florestas do estado de São Paulo foi demonstrada, para florestas semidecíduas, por Salis et al. (1995) e ombrófilas, por Scudeller et al. (2001) e Ivanauskas \& Rodrigues (2000), padrões estes estendido para o sudeste brasileiro por Oliveira-Filho \& Fontes (2000). As áreas do maciço do Itatiaia, com exceção de Bmi-1, apresentaram características florísticas reconhecidas como indicadoras de florestas de maiores altitudes do sudeste do Brasil, ou até mesmo do Neotrópico. Um dos indícios deste comportamento é a riqueza relativa de espécies de Lauraceae, Asteraceae, Cyatheaceae, Solanaceae, Melastomataceae e Aquifoliaceae, que correspondem ao perfil florístico descrito por Oliveira-Filho \& Fontes (2000) para as Florestas Atlânticas Alto-Montanas, tanto Ombrófilas como Semidecíduas. Gentry (1995), analisando 
florestas Andinas e da América Central, constatou uma perda de importância de Fabaceae a partir dos $1.500 \mathrm{~m}$ de altitude, e um aumento no predomínio de Lauraceae, Melastomataceae e Rubiaceae. As duas famílias de maior importância em relação ao número de espécies nas cinco áreas do maciço do Itatiaia, Myrtaceae e Melastomataceae, também são consideradas por Webster (1995) como características de florestas nebulares do Neotrópico, além de outras famílias que também foram encontradas em abundância na região do Itatiaia como Aquifoliaceae, Clethraceae, Clusiaceae, Cunoniaceae, Elaeocarpaceae, Podocarpaceae, Rosaceae, Sabiaceae, Styracaceae, Symplocaceae e Winteraceae.

Os gêneros que contribuíram com maior número de espécies na região do maciço do Itatiaia foram Miconia com 46 espécies, seguida de Ocotea com 27; Eugenia com 21; Casearia com 20; Solanum com 19; Tibouchina com 18; Cyathea, Myrcia e Myrsine com 17 espécies cada; Nectandra com 16; Ilex com 14 e Croton e Machaerium com 13 espécies cada. Juntos, esses gêneros contribuíram com 57\% das espécies registradas. Entre eles, Miconia, Cyathea, Myrsine e Ilex são considerados por Webster (1995) como característicos de florestas nebulares neotropicais, o que foi confirmado para o sudeste do Brasil por Oliveira Filho \& Fontes (2000). Além disso, foram registrados outros gêneros que não se destacaram pelo número de espécies, mas são considerados como fortemente relacionados a altitudes elevadas no Brasil, ou mesmo no Neotrópico, como Clethra, Weinmannia, Drimys, Gordonia, Podocarpus, Myrceugenia, Meliosma, Prunus e Roupala (Webster 1995; Fontes 1997; Oliveira Filho \& Fontes 2000; França \& Stehmann 2004)

O perfil florístico das espécies também mostra relação com florestas montanas. Das 65 espécies apontadas Oliveira-Filho \& Fontes (2000) como indicadoras de floresta atlântica altomontana, 50 (77\%) foram registradas nas áreas do maciço do Itatiaia: Byrsonima laxiflora, Calyptranthes clusiifolia, Casearia obliqua, Cecropia glaziovii, Cinnamomum glaziovii,
Clethra scabra, Clusia criuva, Daphnopsis fasciculata, Drimys brasiliensis, Eremanthus incanus, Euplassa incana, Ficus luschnathiana, F. mexiae, Geonoma schottiana, Gomidesia spectabilis, Gordonia fruticosa, Guatteria australis, Hedyosmum brasiliensis, Leucochloron incuriale, Maytenus glazioviana, M. salicifolia, Meliosma sellowii, Miconia brunnea, M. chartacea, M. cinnamomifolia, Miconia theaezans, Mollinedia argyrogyna, Myrcia laruotteana, Myrsine gardneriana, Nectandra grandiflora, $N$. lanceolata, N. nitidula, N. puberula, Ocotea brachybotra, Ocotea silvestris, Picramnia glazioviana, Pimenta pseudocaryophyllus, Protium widgrenii, Psychotria suterella, Quiina glaziovii, Schefflera angustissima, S. calva, Siphoneugena widgreniana, Solanum bullatum, Symplocos celastrinea, Tabebuia chrysotricha, Tibouchina stenocarpa, Trembleya parviflora, Trichilia emarginata, Vismia brasiliensis e Weinmannia paulliniifolia. Por outro lado, apenas duas das 65 espécies relacionadas por Oliveira-Filho \& Fontes (2000) foram registradas para a área Bmi-1, o que confirma a coerência da classificação do IBGE (Veloso et al. 1991; IBGE 1997), que destaca as formações florestais aluviais, independentemente da altitude em que se encontram, como distintas das formações florestais vinculadas aos pisos altitudinais. Das 82 espécies encontradas em Bmi-1, 15 foram exclusivas dessa área, o que demonstra que o fato de a área sofrer inundações periodicamente pode restringir a colonização dessas áreas por poucas espécies adaptadas às condições de saturação hídrica temporária. Por outro lado, das 76 espécies citadas como de ampla ocorrência nas matas ciliares do Brasil extra-amazônico por Rodrigues \& Nave (2001), 44 (58\%) também foram registradas nas florestas do maciço do Itatiaia, particularmente em Bmi-1. Como todas elas tem pelo menos um setor ripário, pode-se inferir que, mesmo em áreas de altitudes mais elevadas, há um grande número de espécies em comum entre as áreas de matas ciliares extraamazônica. 
Tabela 2 - Relação das 444 espécies arbóreas registradas nas cinco áreas de floresta ombrófila montana do maciço do Itatiaia (MG e RJ). As espécies estão organizadas em ordem alfabética das famílias reconhecidas pelo APG II (2003) e seguidas do registro de ocorrência (x) e au sência (-) nas áreas e do número de registro das amostras no Herbário ESAL.

Famílias/Espécies

ANACARDIACEAE

Astronium graveolens Jacq.

Lithraea molleoides (Vell.) Engler

Schinus terebinthifolius Raddi

Tapirira guianensis Aubl.

Tapirira obtusa (Benth.) Mitchell

\section{ANNONACEAE}

Annona cacans Warm.

Cymbopetalum brasiliense (Vell.) Benth.

Duguetia salicifolia R.E.Fries

Guatteria australis A.St.-Hil.

Guatteria latifolia (Mart.) R.E.Fries

Guatteria pohliana Schltdl.

Guatteria sellowiana Schltdl.

Rollinia dolabripetala (Raddi) R.E.Fries

Rollinia emarginata Schltdl.

Rollinia laurifolia Schltdl.

Rollinia sylvatica (A.St.-Hil.) Mart.

Xylopia brasiliensis Sprengel

\section{APOCYNACEAE}

Aspidosperma australe Müll.Arg.

Aspido sperma olivaceum Müll.Arg.

Aspidosperma parvifolium A.DC.

Aspidosperma spruceanum Benth.

\section{AQUIFOLIACEAE}

Ilex amara (Vell.) Loes.

Ilex cerasifolia Reissek

Ilex conocarpa Reissek

Ilex paraguariensis A.St.-Hil.

Ilex theezans Mart.

\section{ARALIACEAE}

Dendropanax cuneatus (DC.) Decne \& Planch.

Oreopanax capitatus (Jacq.) Decne \& Planch.

Oreopanax fulvus Marchal

Schefflera angustissima (Marchal) Frodin

Schefflera calva (Cham.) Frodin \& Fiaschi

\section{ARAUCARIACEAE}

Araucaria angustifolia (Bert.) Kuntze

ARECACEAE

Euterpe edulis Mart.

Geonoma schottiana Mart.

Syagrus romanzoffiana (Cham.) Glassman

\section{Bmi-1 Bmi-2 Bmi-3 Aiu Vma Registro}

$\begin{array}{lllllr}- & - & - & - & x & 17992 \\ - & - & - & x & - & 16364 \\ - & - & - & - & x & 16722 \\ - & x & - & x & - & 15135 \\ - & x & - & x & - & 15141 \\ & & & & & \\ \text { X } & \text { X } & - & x & - & 19943 \\ - & x & - & x & - & 17230 \\ - & x & x & - & - & 19944 \\ - & x & x & x & x & 15137 \\ - & x & x & x & - & 17232 \\ - & x & - & - & - & 17233 \\ - & - & x & - & - & 785 \\ - & x & - & x & x & 16221 \\ x & - & - & x & - & 19945 \\ - & x & - & x & - & 17062 \\ - & x & - & - & - & 17234 \\ - & x & - & - & - & 17234\end{array}$

$\begin{array}{llllll}- & \mathrm{x} & - & - & - & 15821 \\ - & - & - & \mathrm{x} & - & 17044 \\ \mathrm{x} & \mathrm{x} & \mathrm{x} & - & \mathrm{x} & 17063 \\ - & \mathrm{X} & - & \mathrm{x} & - & 17235\end{array}$

\begin{tabular}{|c|c|c|c|c|c|}
\hline X & - & - & - & $\mathrm{X}$ & 19946 \\
\hline- & $\mathrm{x}$ & - & $\mathrm{x}$ & - & 17237 \\
\hline- & $\mathrm{x}$ & $\mathrm{x}$ & - & - & 19947 \\
\hline- & - & $\mathrm{x}$ & - & $\mathrm{X}$ & 16226 \\
\hline $\mathrm{X}$ & $\mathrm{x}$ & - & - & X & 17239 \\
\hline- & - & - & $\mathrm{x}$ & - & 12311 \\
\hline- & $\mathrm{x}$ & - & - & - & 17240 \\
\hline- & - & - & - & $\mathrm{X}$ & - \\
\hline- & - & - & - & $\mathrm{X}$ & 16712 \\
\hline- & $\mathrm{x}$ & $\mathrm{x}$ & $\mathrm{x}$ & - & 17241 \\
\hline- & $\mathrm{x}$ & $\mathrm{X}$ & $\mathrm{X}$ & $\mathrm{X}$ & 17243 \\
\hline- & - & - & $\mathrm{X}$ & $\mathrm{X}$ & 15153 \\
\hline- & $\mathrm{x}$ & - & $\mathrm{x}$ & - & 15156 \\
\hline $\mathrm{X}$ & - & - & $\mathrm{X}$ & - & 1744 \\
\hline
\end{tabular}


ASTERACEAE

Austrocritonia velutina (Gardner)

R.M.King \& H.Robinson

Austroeupatorium inulaefolium (Kunth)

R.M.King \& H.Robinson

Baccharis brachylaenoides DC.

Baccharis serrulata Pers.

Dasyphyllum brasiliense (Sprengel) Cabrera

Eremanthus erythropappus (DC.) MacLeish

Eremanthus incanus (Less.) Less.

Gochnatia paniculata (Less.) Cabrera

Gochnatia polymorpha (Less.) Cabrera

Heterocondylus vauthierianus (DC.)

R.M.King \& H.Robinson

Piptocarpha macropoda Baker

Piptocarpha organensis Cabrera

Piptocarpha regnellii (Sch.Bip.) Cabrera

Stifftia chrysantha Mikan

Verbesina claussenii Sch.Bip.

Vernonanthura diffusa (Less.) H.Robinson

Vernonanthura discolor (Sprengel) H.Robinson

Vernonanthura phosphorica (Vell.) H.Robinson

BIGNONIACEAE

Cybistax antisyphillitica Mart.

Jacaranda macrantha Cham.

Tabebuia alba (Cham.) Sandw.

Tabebuia chrysotricha (Mart.) Standley

Tabebuia heptaphylla (Vell.) Toledo

Tabebuia serratifolia (Vahl) Nichols

Tabebuia velloso $i$ Toledo

\begin{tabular}{|c|c|c|c|c|c|}
\hline $\mathrm{X}$ & - & - & - & - & 19948 \\
\hline- & - & - & $\mathrm{x}$ & - & - \\
\hline $\mathrm{x}$ & - & $\mathrm{x}$ & - & - & 2883 \\
\hline- & $\mathrm{x}$ & $\mathrm{x}$ & - & - & 17244 \\
\hline- & - & $\mathrm{x}$ & $\mathrm{x}$ & - & 19949 \\
\hline- & $\mathrm{x}$ & $\mathrm{x}$ & $\mathrm{x}$ & $\mathrm{X}$ & 18213 \\
\hline- & - & - & - & $\mathrm{x}$ & 15154 \\
\hline- & $\mathrm{X}$ & $\mathrm{x}$ & $\mathrm{x}$ & - & 15151 \\
\hline- & - & - & $\mathrm{x}$ & $\mathrm{X}$ & 16420 \\
\hline- & - & $\mathrm{x}$ & - & - & 19950 \\
\hline- & $\mathrm{x}$ & $\mathrm{x}$ & $\mathrm{x}$ & - & 16744 \\
\hline- & - & - & - & $\mathrm{x}$ & - \\
\hline - & $\mathrm{x}$ & $\mathrm{x}$ & - & $\mathrm{X}$ & 19951 \\
\hline- & $\mathrm{x}$ & - & - & - & 17247 \\
\hline- & - & - & - & $\mathrm{X}$ & - \\
\hline $\mathrm{x}$ & $\mathrm{x}$ & $\mathrm{x}$ & $\mathrm{x}$ & $\mathrm{x}$ & 17647 \\
\hline- & $\mathrm{x}$ & $\mathrm{x}$ & $\mathrm{x}$ & $\mathrm{X}$ & 17250 \\
\hline- & - & - & $\mathrm{x}$ & - & 16746 \\
\hline $\mathrm{X}$ & $\mathrm{x}$ & - & - & - & 16747 \\
\hline- & $\mathrm{x}$ & - & $\mathrm{x}$ & - & 17074 \\
\hline- & - & $\mathrm{x}$ & - & - & 19952 \\
\hline- & $\mathrm{x}$ & - & $\mathrm{x}$ & - & 17251 \\
\hline $\mathrm{X}$ & - & - & - & - & 19953 \\
\hline- & - & - & $\mathrm{x}$ & - & 17075 \\
\hline- & $\mathrm{x}$ & - & $\mathrm{x}$ & - & 17252 \\
\hline- & $\mathrm{X}$ & - & $\mathrm{X}$ & - & 17253 \\
\hline- & - & - & $\mathrm{X}$ & - & 12348 \\
\hline- & $\mathrm{x}$ & - & - & - & 15143 \\
\hline- & - & - & $\mathrm{X}$ & - & 16759 \\
\hline- & - & - & $\mathrm{x}$ & $\mathrm{X}$ & 16400 \\
\hline $\mathrm{x}$ & - & - & - & $\mathrm{X}$ & 19954 \\
\hline- & - & - & $\mathrm{X}$ & - & 16940 \\
\hline- & - & - & $\mathrm{x}$ & - & 16619 \\
\hline- & - & $\mathrm{X}$ & - & - & 18785 \\
\hline- & $\mathrm{x}$ & - & $\mathrm{x}$ & - & 17254 \\
\hline- & - & - & - & $\mathrm{x}$ & 13233 \\
\hline $\mathrm{x}$ & - & $\mathrm{x}$ & - & - & 19955 \\
\hline- & $\mathrm{x}$ & - & $\mathrm{x}$ & - & 17255 \\
\hline
\end{tabular}

BORAGINACEAE

Cordia ecalyculata Vell.

Cordia sellowiana Cham.

Cordia superba Cham.

BURSERACEAE

Protium spruceanum (Benth.) Engler

Protium widgrenii Engler

CANELLACEAE

Cinnamodendron dinisii Schwacke

CANNABACEAE

Celtis ehrenbergiana (Klotzsch) Liebm.

Trema micrantha (L.) Blume

CELASTRACEAE

Maytenus evonymoides Reissek

Maytenus glazioviana Loes.

Maytenus gonoclada Mart.

Maytenus robusta Reissek

Maytenus salicifolia Reissek 
Famílias/Espécies

\section{CHLORANTHACEAE}

Hedyo smum brasiliense Mart.

\section{CLETHRACEAE}

Clethra scabra Pers.

\section{CLUSIACEAE}

Clusia criuva Cambess.

Clusia fragrans Gardner

Clusia parviflora Humb. \& Bonpl.

Garcinia gardneriana (Planch. \& Triana) Zappi

Tovomitopsis saldanhae Engler

\section{COMBRETACEAE}

Terminalia glabrescens Mart.

\section{CUNONIACEAE}

Lamanonia grandistipularis (Taub.) Taub.

Lamanonia ternata Vell.

Weinmannia hirta Swartz

Weinmannia humilis Engler

Weinmannia paulliniifolia Pohl

\section{CYATHEACEAE}

Alsophila setosa Kaulf

Alsophila sternbergii (Sternb.) Conant

Cyathea atrovirens (Langsd.\& Fisch.) Domin

Cyathea corcovadensis (Raddi) Domin

Cyathea delgadii Sternb.

Cyathea dichromatolepis (Fée) Domin

Cyathea glaziovii (Fée) Domin

Cyathea phalerata Mart.

Cyathea villosa Willd.

Sphaeropteris gardneri (Hook.) Tryon

\section{DICHAPETALACEAE}

Stephanopodium organense (Rizz.) Prance

DICKSONIACEAE

Dicksonia sellowiana Hook.

\section{ELAEOCARPACEAE}

Sloanea guianensis (Aubl.) Benth.

Sloanea monosperma Vell.

\section{ERICACEAE}

Agarista eucalyptoides (Cham. \& Schltdl.) G.Don Agarista glaberrima (Sleumer) Judd

\section{ERYTHROXYLACEAE}

Erythroxylum cuneifolium (Mart.) O.E.Schulz Erythroxylum deciduum A.St.-Hil.

Erythroxylum pelleterianum A.St.-Hil.

\section{Bmi-1 Bmi-2 Bmi-3 Aiu Vma Registro}

$\begin{array}{llllll}\text { X } & \mathrm{X} & \mathrm{X} & \mathrm{X} & - & 15170\end{array}$

$\begin{array}{cccccc}- & \mathrm{X} & \mathrm{X} & \mathrm{X} & \mathrm{X} & 17086 \\ - & \mathrm{x} & - & - & - & 16236 \\ - & \mathrm{x} & - & - & - & 17256 \\ - & - & - & - & \mathrm{x} & - \\ - & - & - & \mathrm{x} & - & 16454 \\ - & \mathrm{X} & - & \mathrm{x} & - & 17257 \\ & & & & & \\ - & - & - & \mathrm{x} & - & 16410\end{array}$

15157

18372

$-$

$-$

19959

19956

19957

19958

17260

17261

19959

$-$

17263

13322

17264

\section{ESCALLONIACEAE}

Escallonia bifida Link. \& Otto 
Famílias/Espécies

\section{EUPHORBIACEAE}

Alchornea glandulosa Poepp. \& Endl.

Alchornea sidifolia Müll.Arg.

Alchornea triplinervia (Sprengel) Müll.Arg.

Aparisthmium cordatum (Juss.) Bail.

Croton celtidifolius Bail.

Croton floribundus Sprengel

Croton hecatomandrum Müll.Arg.

Croton organensis Bail.

Croton salutaris Casar.

Croton verrucosus Radcl.-Sm. \& Govaerts

Gymnanthes concolor (Sprengel) Müll.Arg.

Manihot pilosa Pohl

Pachystroma longifolium (Nees) Johnston

Pera glabrata (Schott) Poepp.

Sapium glandulosum (L.) Morong

Sapium haematospermum Müll.Arg.

Sebastiania brasiliensis Sprengel

Sebastiania commersoniana (Bail.) Smith \& Downs

Tetrorchidium parvulum Müll.Arg.

\section{FABACEAE-CAESALPINIOIDEAE}

Bauhinia forficata Link

Cassia ferruginea (Schrad.) Schrad.

Copaifera langsdorffii Desf.

Poeppigia procera Presl.

Sclerolobium rugosum Mart.

Senna macranthera (Collad.) Irwin \& Barneby

Senna multijuga (L.C.Rich.) Irwin \& Barneby

FABACEAE-FABOIDEAE

Dalbergia frutescens (Vell.) Britton

Dalbergia villosa (Benth.) Benth.

Erythrina falcata Benth.

Machaerium brasiliense Vogel

Machaerium condensatum Kuhlm. \& Hoehne

Machaerium hirtum (Vell.) Stellfeld

Machaerium lanceolatum (Vell.) Macbr.

Machaerium minutiflorum Tul.

Machaerium nictitans (Vell.) Benth.

Machaerium reticulatum (Peyr.) Pers.

Machaerium villosum Vogel

Ormosiafastigiata Tul.

Ormosia friburgensis Taub.

Platycyamus regnellii Benth.

\section{FABACEAE-MIMOSOIDEAE}

Acacia polyphylla DC.

Albizia edwallii (Hoehne) Barneby \& Grimes

Albizia polycephala (Benth.) Killip

Anadenanthera colubrina (Vell.) Brenan

Calliandra tweediei Benth.
Bmi-1 Bmi-2 Bmi-3 Aiu Vma Registro

\begin{tabular}{|c|c|c|c|c|c|}
\hline $\mathrm{x}$ & $\mathrm{X}$ & - & - & $\mathrm{x}$ & 17096 \\
\hline - & $\mathrm{X}$ & $\mathrm{X}$ & $\mathrm{x}$ & $\mathrm{x}$ & 17268 \\
\hline - & $\mathrm{x}$ & $\mathrm{X}$ & $\mathrm{X}$ & $\mathrm{x}$ & 17097 \\
\hline - & - & - & $\mathrm{x}$ & - & 14881 \\
\hline- & - & $\mathrm{x}$ & - & $\mathrm{x}$ & 19961 \\
\hline $\mathrm{X}$ & $\mathrm{X}$ & - & $\mathrm{X}$ & $\mathrm{x}$ & 17099 \\
\hline- & - & - & - & $\mathrm{x}$ & - \\
\hline - & $\mathrm{X}$ & $\mathrm{X}$ & $\mathrm{X}$ & - & 17269 \\
\hline - & $\mathrm{X}$ & - & - & - & 17270 \\
\hline - & - & $\mathrm{X}$ & $\mathrm{X}$ & - & 12361 \\
\hline - & - & - & $\mathrm{X}$ & - & 19962 \\
\hline- & $\mathrm{X}$ & - & $\mathrm{X}$ & - & 17271 \\
\hline- & - & - & - & $\mathrm{x}$ & 13031 \\
\hline- & $\mathrm{X}$ & - & $\mathrm{X}$ & - & 17104 \\
\hline $\mathrm{X}$ & $\mathrm{X}$ & $\mathrm{X}$ & $\mathrm{X}$ & $\mathrm{x}$ & 15382 \\
\hline $\mathrm{x}$ & - & - & - & - & 19963 \\
\hline $\mathrm{X}$ & - & - & $\mathrm{X}$ & - & 19964 \\
\hline $\mathrm{X}$ & - & - & $\mathrm{X}$ & - & 19004 \\
\hline - & $\mathrm{X}$ & $\mathrm{X}$ & - & - & 19965 \\
\hline
\end{tabular}

17125

19967

16491

17273

17274

19197

17275

17016

18026

17277

18029

19969

18030

17020

16519

18031

17278

16520

17279

$-$

16524

17627

$-$

18037

19184
1510 


\begin{tabular}{|c|c|c|c|c|c|c|}
\hline Famílias/Espécies & Bmi-1 & Bmi-2 & Bmi-3 & Aiu & Vma & Registro \\
\hline Inga marginata Willd. & - & - & - & - & $\mathrm{x}$ & 17136 \\
\hline Inga sessilis (Vell.) Mart. & - & $\mathrm{x}$ & $\mathrm{x}$ & - & $\mathrm{x}$ & 17281 \\
\hline Inga striata Benth. & - & $\mathrm{x}$ & - & $\mathrm{x}$ & $\mathrm{x}$ & 17282 \\
\hline Inga vulpina Mart. & $\mathrm{x}$ & $\mathrm{x}$ & $\mathrm{x}$ & $\mathrm{x}$ & - & 17283 \\
\hline Leucochloron incuriale (Vell.) Barneby \& Grimes & - & - & - & $\mathrm{x}$ & $\mathrm{x}$ & 18042 \\
\hline Mimo sa artemisiana Heringer \& Paula & $\mathrm{x}$ & $\mathrm{x}$ & - & - & - & 19266 \\
\hline Mimo sa scabrela Benth. & - & - & $\mathrm{x}$ & - & $\mathrm{x}$ & 19968 \\
\hline Piptadenia gonoacantha (Mart.) Macbr. & - & - & - & $\mathrm{x}$ & $\mathrm{x}$ & 16507 \\
\hline \multicolumn{7}{|l|}{ GRISELINIACEAE } \\
\hline Griselinia ruscifolia (Clos) Taub. & - & - & - & - & $\mathrm{x}$ & - \\
\hline \multicolumn{7}{|l|}{ HYPERICACEAE } \\
\hline Vismia brasiliensis Choisy & - & $\mathrm{x}$ & - & $\mathrm{x}$ & - & 15164 \\
\hline Vismia guianensis (Aubl.) Pers. & - & - & - & $\mathrm{x}$ & - & 15792 \\
\hline \multicolumn{7}{|l|}{ LAMIACEAE } \\
\hline Aegiphila fluminensis Vell. & - & $\mathrm{x}$ & $\mathrm{x}$ & $\mathrm{x}$ & - & 17374 \\
\hline Aegiphila obducta Vell. & $\mathrm{x}$ & - & $\mathrm{x}$ & - & $\mathrm{x}$ & 20017 \\
\hline Aegiphila sellowiana Cham. & - & - & - & $\mathrm{x}$ & $\mathrm{x}$ & 12677 \\
\hline Clerodendron fragrans Willd. & & - & $\mathrm{x}$ & - & - & - \\
\hline Hyptidendron asperrimum (Epling) Harley & - & $\mathrm{x}$ & - & - & - & 17290 \\
\hline Vitex cymosa Bert. & - & - & - & $\mathrm{x}$ & $\mathrm{x}$ & 16623 \\
\hline Vitex megapotamica (Sprengel) Moldenke & $\mathrm{x}$ & - & - & - & - & 19970 \\
\hline Vitex polygama Cham. & - & - & - & $\mathrm{x}$ & - & 13009 \\
\hline \multicolumn{7}{|l|}{ LAURACEAE } \\
\hline Aiouea saligna Meisn. & - & - & - & - & $\mathrm{x}$ & - \\
\hline Beilschmiedia rigida $(\mathrm{Mez})$ Kosterm. & - & - & - & - & $\mathrm{x}$ & - \\
\hline Cinnamoтиm glaziovii (Mez) Vattimo-Gil & - & $\mathrm{x}$ & - & - & $\mathrm{x}$ & 19971 \\
\hline Cryptocarya aschersoniana $\mathrm{Mez}$ & - & - & - & $\mathrm{x}$ & - & 16526 \\
\hline Cryptocarya saligna $\mathrm{Mez}$ & - & - & - & - & $\mathrm{x}$ & - \\
\hline Endlicheria paniculata (Sprengel) Macbr. & - & $\mathrm{x}$ & - & $\mathrm{x}$ & $\mathrm{x}$ & 17291 \\
\hline Licaria armeniaca (Nees) Kosterm. & - & - & - & - & $\mathrm{x}$ & 17706 \\
\hline Nectandra grandiflora Nees & - & $\mathrm{x}$ & $\mathrm{x}$ & $\mathrm{x}$ & $\mathrm{x}$ & 17115 \\
\hline Nectandra lanceolata Nees & $\mathrm{x}$ & $\mathrm{x}$ & - & $\mathrm{x}$ & - & 17292 \\
\hline Nectandra membranacea (Swartz) Griseb. & - & - & - & - & $\mathrm{x}$ & 17293 \\
\hline Nectandra nitidula Nees & - & - & - & $\mathrm{x}$ & - & 16530 \\
\hline Nectandra oppositifolia Nees & - & $\mathrm{x}$ & - & $\mathrm{x}$ & $\mathrm{x}$ & 15394 \\
\hline Nectandra puberula (Schott) Nees & - & $\mathrm{x}$ & - & - & $\mathrm{x}$ & 17294 \\
\hline Nectandra reticulata (Ruiz \& Pav.) Mez & - & - & - & - & $\mathrm{x}$ & - \\
\hline Ocotea aciphylla (Nees) Mez & - & $\mathrm{x}$ & $\mathrm{x}$ & - & $\mathrm{x}$ & 19972 \\
\hline Ocotea brachybotra (Meisn.) Mez & - & $\mathrm{x}$ & - & - & $\mathrm{x}$ & 15397 \\
\hline Ocotea corymbosa (Meisn.) Mez & - & $\mathrm{x}$ & $\mathrm{x}$ & $\mathrm{x}$ & $\mathrm{x}$ & 18015 \\
\hline Ocotea diospyrifolia (Meisn.) Mez & $\mathrm{x}$ & - & - & $\mathrm{x}$ & - & 17118 \\
\hline Ocotea dispersa (Nees) Mez & - & - & - & $\mathrm{x}$ & - & 15050 \\
\hline Ocotea elegans $\mathrm{Mez}$ & - & $\mathrm{x}$ & $\mathrm{x}$ & $\mathrm{x}$ & - & 19973 \\
\hline Ocotea indecora $(\mathrm{Schott}) \mathrm{Mez}$ & $\mathrm{x}$ & - & - & - & $\mathrm{x}$ & 19974 \\
\hline Ocotea laxa (Nees) Mez & - & - & - & - & $\mathrm{x}$ & 15398 \\
\hline Ocotea longifolia Kunth & - & $\mathrm{x}$ & - & - & - & 17295 \\
\hline Ocotea notata (Nees \& Mart.) Mez & - & - & - & - & $\mathrm{x}$ & 19616 \\
\hline Ocotea odorifera (Vell.) Rohwer & - & $\mathrm{x}$ & - & $\mathrm{x}$ & - & 15402 \\
\hline
\end{tabular}




Famílias/Espécies
Ocotea puberula (Rich.) Nees
Ocotea pulchella Mart.
Ocotea silvestris Vattimo-Gil
Persea fulva Kopp
Persea pyrifolia Nees
Persea venosa Nees
Rhodo stemonodaphne macrocalyx (Meisn.) Rohwer

\begin{tabular}{llllll} 
Bmi-1 & Bmi-2 & Bmi-3 & Aiu & Vma & Registro \\
\hline X & X & - & X & X & 16632 \\
X & - & - & - & - & 15403 \\
- & - & X & - & - & 19975 \\
- & X & - & - & - & 17296 \\
- & X & X & X & X & 18425 \\
- & X & X & - & - & 19976 \\
- & - & - & - & $x$ & 18274 \\
& & & & & \\
- & X & - & - & - & 17299
\end{tabular}

Couratari pyramidata (Vell.) R.Knuth.

\section{LYTHRACEAE}

Lafoensia densiflora Pohl

Lafoensia pacari A.St.-Hil.

Lafoensia vandelliana Cham. \& Schltdl.

\section{MALPIGHIACEAE}

Byrsonima laxiflora Griseb.

Byrsonima myricifolia Griseb.

Byrsonima stipulacea A.Juss.

\section{MALVACEAE}

Ceiba speciosa (A.St.-Hil.) Ravenna

Luehea divaricata Mart. \& Zucc.

Pseudobombax grandiflorum (Cav.) A.Robyns

\section{MELASTOMATACEAE}

Huberia nettoana Brade

Leandra aurea (Cham.) Cogn.

Leandra barbinervis (Cham.) Cogn.

Leandra lancifolia Cogn.

Leandra melastomoides Raddi

Leandra scabra DC.

Leandra sublanata Cogn.

Meriania claussenii Triana

Meriania glabra Triana

Miconia brunnea Mart.

Miconia calvescens DC.

Miconia castaneifolia Naud.

Miconia chamissois Naud.

Miconia chartacea Triana

Miconia cinerascens Miq.

Miconia cinnamomifolia (DC.) Naud.

Miconia conferta DC.

Miconia corallina Spring

Miconia cubatanensis Hoehne

Miconia divaricata Gardner

Miconia eichlerii Cogn.

Miconia fasciculata Gardner

Miconia inconspicua Miq.

Miconia latecrenata (DC.) Naud.

Miconia ligustroides (DC.) Naud.

Miconia minutiflora (Bonpl.) DC.

\begin{tabular}{|c|c|c|c|c|c|}
\hline- & - & - & - & $\mathrm{x}$ & 16541 \\
\hline- & $\mathrm{x}$ & - & - & - & 17300 \\
\hline - & $\mathrm{x}$ & - & - & - & 17301 \\
\hline - & - & - & $\mathrm{x}$ & - & 16393 \\
\hline - & - & - & $\mathrm{x}$ & - & 16616 \\
\hline - & $\mathrm{x}$ & - & - & - & 17302 \\
\hline - & X & - & - & $\mathrm{x}$ & 17303 \\
\hline - & - & - & $\mathrm{x}$ & - & 17303 \\
\hline - & - & - & - & $\mathrm{x}$ & 17140 \\
\hline - & - & $\mathrm{x}$ & - & - & 19978 \\
\hline - & - & - & $\mathrm{x}$ & - & 12887 \\
\hline - & $\mathrm{x}$ & $\mathrm{x}$ & $\mathrm{x}$ & - & 17141 \\
\hline - & - & - & - & $\mathrm{x}$ & 9905 \\
\hline - & $\mathrm{x}$ & - & - & $\mathrm{X}$ & 17304 \\
\hline- & - & - & - & $\mathrm{x}$ & - \\
\hline - & $\mathrm{x}$ & - & $\mathrm{x}$ & - & 17305 \\
\hline - & - & - & $\mathrm{x}$ & - & 15101 \\
\hline- & - & - & - & $\mathrm{x}$ & - \\
\hline- & - & - & $\mathrm{x}$ & - & 11637 \\
\hline- & $\mathrm{x}$ & $\mathrm{x}$ & $\mathrm{x}$ & - & 15439 \\
\hline- & $\mathrm{x}$ & $\mathrm{x}$ & - & - & 17306 \\
\hline- & $\mathrm{x}$ & $\mathrm{x}$ & $\mathrm{x}$ & - & 17307 \\
\hline- & - & - & - & $\mathrm{X}$ & - \\
\hline- & - & - & - & $\mathrm{x}$ & 15436 \\
\hline $\mathrm{x}$ & $\mathrm{x}$ & - & $\mathrm{x}$ & - & 19979 \\
\hline- & - & $\mathrm{x}$ & - & - & 19980 \\
\hline- & $\mathrm{x}$ & $\mathrm{x}$ & $\mathrm{x}$ & - & 17309 \\
\hline- & $\mathrm{x}$ & $\mathrm{x}$ & - & - & 19981 \\
\hline- & - & - & - & $\mathrm{x}$ & PED-12 \\
\hline- & $\mathrm{x}$ & $\mathrm{x}$ & $\mathrm{x}$ & - & 17310 \\
\hline- & - & - & $\mathrm{x}$ & - & 16547 \\
\hline- & $\mathrm{x}$ & - & $\mathrm{x}$ & $\mathrm{X}$ & 15434 \\
\hline
\end{tabular}




\begin{tabular}{|c|c|c|c|c|c|c|}
\hline Famílias/Espécies & Bmi-1 & Bmi-2 & Bmi-3 & Aiu & Vma & Registro \\
\hline Miconia paulensis Naud. & - & - & - & - & $\mathrm{x}$ & 4062 \\
\hline Miconia prasina (Swartz) DC. & $\mathrm{x}$ & $\mathrm{x}$ & $\mathrm{x}$ & - & - & 19982 \\
\hline Miconia pusilliflora (DC.) Triana & $\mathrm{x}$ & $\mathrm{x}$ & $\mathrm{x}$ & - & - & 19983 \\
\hline Miconia sellowiana Naud. & - & $\mathrm{x}$ & $\mathrm{x}$ & $\mathrm{x}$ & $\mathrm{x}$ & 17312 \\
\hline Miconia theaezans (Bonpl.) Cogn & - & - & $\mathrm{x}$ & - & $\mathrm{x}$ & 19984 \\
\hline Miconia trianae Cogn. & - & - & - & $\mathrm{x}$ & $\mathrm{x}$ & 16549 \\
\hline Miconia tristis Spring & - & - & - & $\mathrm{x}$ & - & 18288 \\
\hline Miconia urophylla DC. & - & $\mathrm{x}$ & - & $\mathrm{x}$ & - & 17313 \\
\hline Tibouchina adenostemon (DC.) Cogn. & - & - & - & - & $\mathrm{x}$ & 13293 \\
\hline Tibouchina arborea (Gardner) Cogn. & - & $\mathrm{x}$ & $\mathrm{x}$ & - & $\mathrm{x}$ & 19985 \\
\hline Tibouchina estrellensis (Raddi) Cogn. & - & - & - & - & $\mathrm{x}$ & - \\
\hline Tibouchina granulosa Cogn. & - & - & - & $\mathrm{x}$ & - & 15099 \\
\hline Tibouchina moricandiana (DC.) Bail. & $\mathrm{x}$ & $\mathrm{x}$ & - & - & $\mathrm{x}$ & 19986 \\
\hline Tibouchina mutabilis Cogn. & - & $\mathrm{x}$ & $\mathrm{x}$ & - & $\mathrm{x}$ & 19987 \\
\hline Tibouchina pulchra Cogn. & - & $\mathrm{x}$ & $\mathrm{x}$ & - & - & 17316 \\
\hline Tibouchina sellowiana (Cham.) Cogn. & - & $\mathrm{x}$ & $\mathrm{x}$ & - & $\mathrm{x}$ & 16258 \\
\hline Tibouchina semidecandra (DC.) Cogn. & - & - & - & - & $\mathrm{x}$ & - \\
\hline Tibouchina stenocarpa (DC.) Cogn. & - & - & - & - & $\mathrm{x}$ & 14496 \\
\hline Trembleya parviflora (D.Don) Cogn. & - & - & $\mathrm{x}$ & - & $\mathrm{x}$ & 15431 \\
\hline \multicolumn{7}{|l|}{ MELIACEAE } \\
\hline Cabralea canjerana (Vell.) Mart. & - & $\mathrm{x}$ & $\mathrm{x}$ & $\mathrm{x}$ & $\mathrm{x}$ & 15465 \\
\hline Cedrela fissilis Vell. & - & $\mathrm{x}$ & $\mathrm{x}$ & $\mathrm{x}$ & $\mathrm{x}$ & 16553 \\
\hline Guarea kunthiana A.Juss. & - & $\mathrm{x}$ & - & $\mathrm{x}$ & - & 17149 \\
\hline Trichilia elegans A.Juss. & - & - & - & $\mathrm{x}$ & - & 15770 \\
\hline Trichilia emarginata (Turcz.) C.DC. & $\mathrm{x}$ & - & - & $\mathrm{x}$ & - & 15429 \\
\hline Trichilia hirta L. & - & $\mathrm{x}$ & - & $\mathrm{x}$ & - & 14964 \\
\hline Trichilia pallida Swartz & - & - & - & $\mathrm{x}$ & - & 16863 \\
\hline \multicolumn{7}{|l|}{ MONIMIACEAE } \\
\hline Hennecartia omphalandra J.Poiss. & - & - & - & - & $\mathrm{x}$ & - \\
\hline Mollinedia argyrogyna Perkins & - & - & - & $\mathrm{x}$ & - & 16558 \\
\hline Mollinedia clavigera Tul. & - & - & $\mathrm{x}$ & - & - & 15428 \\
\hline Mollinedia engleriana Perkins & - & $\mathrm{x}$ & - & - & - & 17317 \\
\hline Mollinedia longifolia Tul. & - & $\mathrm{x}$ & - & - & - & 17318 \\
\hline Mollinedia schottiana (Sprengel) Perkins & - & - & - & $\mathrm{x}$ & - & 17613 \\
\hline Mollinedia triflora (Sprengel) Tul. & - & $\mathrm{x}$ & - & - & $\mathrm{x}$ & 17319 \\
\hline Mollinedia widgrenii A.DC. & - & - & - & $\mathrm{x}$ & $\mathrm{x}$ & 13102 \\
\hline \multicolumn{7}{|l|}{ MORACEAE } \\
\hline Ficus gomelleira Kunth \& Bouché & - & - & - & - & $\mathrm{x}$ & 13335 \\
\hline Ficus luschnathiana (Miq.) Miq. & - & $\mathrm{x}$ & - & - & - & 17320 \\
\hline Ficus mexiae Standley & - & $\mathrm{x}$ & $\mathrm{x}$ & $\mathrm{x}$ & - & 15426 \\
\hline Ficuspertusa L.f. & - & - & - & $\mathrm{x}$ & - & 18948 \\
\hline Maclura tinctoria (L.) Steud. & - & - & - & $\mathrm{x}$ & - & 16562 \\
\hline Naucleopsis oblongifolia (Kuhlman) Carauta & - & - & - & - & $\mathrm{x}$ & 17554 \\
\hline Sorocea bonplandii (Bail.) W.Burger & $\mathrm{x}$ & $\mathrm{x}$ & $\mathrm{x}$ & $\mathrm{x}$ & $\mathrm{x}$ & 17321 \\
\hline \multicolumn{7}{|l|}{ MYRISTICACEAE } \\
\hline Virola bicuhyba (Schott) Warb. & - & $\mathrm{x}$ & - & - & $\mathrm{x}$ & 12457 \\
\hline \multicolumn{7}{|l|}{ MYRSINACEAE } \\
\hline Cybianthus peruvianus (A.DC.) Miq. & - & - & - & $\mathrm{x}$ & - & 16261 \\
\hline Myrsine coriacea (Swartz) Roem. \& Schult. & - & $\mathrm{x}$ & $\mathrm{x}$ & $\mathrm{x}$ & $\mathrm{x}$ & 15422 \\
\hline
\end{tabular}




\begin{tabular}{|c|c|c|c|c|c|c|}
\hline Famílias/Espécies & Bmi-1 & Bmi-2 & Bmi-3 & Aiu & Vma & Registro \\
\hline Myrsine gardneriana A.DC. & $\mathrm{x}$ & $\mathrm{x}$ & $\mathrm{x}$ & $\mathrm{x}$ & $\mathrm{x}$ & 17322 \\
\hline Myrsine lineata (Mez) Imkhan. & - & - & $\mathrm{x}$ & - & - & 19989 \\
\hline Myrsine umbellata Mart. & - & $\mathrm{x}$ & $\mathrm{x}$ & $\mathrm{x}$ & $\mathrm{x}$ & 17167 \\
\hline Myrsine villosissima Mart. & - & - & $\mathrm{x}$ & - & - & 19988 \\
\hline \multicolumn{7}{|l|}{ MYRTACEAE } \\
\hline Blepharocalyx salicifolius (Kunth) O.Berg & $\mathrm{x}$ & $\mathrm{x}$ & - & $\mathrm{x}$ & $\mathrm{x}$ & 17325 \\
\hline Calycorectes acutatus (Miq.) Toledo & - & - & - & $\mathrm{x}$ & - & 16465 \\
\hline Calyptranthes clusiifolia O.Berg & - & - & - & $\mathrm{x}$ & $\mathrm{x}$ & 14467 \\
\hline Calyptranthes concinna DC. & - & - & - & $\mathrm{x}$ & $\mathrm{x}$ & 15417 \\
\hline Calyptranthes grandifolia O.Berg & $\mathrm{x}$ & - & - & - & - & 19991 \\
\hline Calyptranthes widgreniana O.Berg & $\mathrm{x}$ & $\mathrm{x}$ & - & - & - & 19992 \\
\hline Campomanesia guaviroba (DC.) Kiaersk. & - & $\mathrm{x}$ & - & $\mathrm{x}$ & - & 19993 \\
\hline Campomanesia guazumifolia (Cambess.) O.Berg & $\mathrm{x}$ & - & - & - & $\mathrm{x}$ & 17169 \\
\hline Campomanesia laurifolia Gardner & $\mathrm{x}$ & $\mathrm{x}$ & - & - & - & 16024 \\
\hline Campomanesia xanthocarpa O.Berg & - & - & - & $\mathrm{x}$ & - & 16472 \\
\hline Eugenia brasiliensis Lam. & - & $\mathrm{x}$ & - & - & - & 17331 \\
\hline Eugenia cerasiflora Miq. & $\mathrm{x}$ & $\mathrm{x}$ & - & - & - & 19994 \\
\hline Eugenia dodonaeifolia Cambess. & - & - & $\mathrm{x}$ & - & - & 14500 \\
\hline Eugeniaflorida DC. & - & - & - & $\mathrm{x}$ & - & 19995 \\
\hline Eugenia hyemalis Cambess. & - & - & - & $\mathrm{x}$ & - & 16883 \\
\hline Eugenia involucrata DC. & - & $\mathrm{x}$ & - & $\mathrm{x}$ & $\mathrm{x}$ & 17172 \\
\hline Eugenia mansoi O.Berg & $\mathrm{x}$ & - & - & $\mathrm{x}$ & - & 19995 \\
\hline Eugenia pluriflora DC. & - & - & - & $\mathrm{x}$ & $\mathrm{x}$ & 11040 \\
\hline Eugenia prasina $\mathrm{O} . \mathrm{Berg}$ & - & - & - & - & $\mathrm{x}$ & - \\
\hline Eugenia sonderiana O.Berg & - & - & - & - & $\mathrm{x}$ & - \\
\hline Gomidesia anacardiifolia (Gardner) O.Berg & - & - & $\mathrm{x}$ & - & $\mathrm{x}$ & 15319 \\
\hline Gomidesia sellowiana O.Berg & - & - & - & - & $\mathrm{x}$ & 16046 \\
\hline Marlierea excoriata Mart. & $\mathrm{x}$ & - & - & - & - & 17175 \\
\hline Marlierea racemosa (Vell.) Kiaersk. & $\mathrm{x}$ & $\mathrm{x}$ & - & $\mathrm{x}$ & - & 19998 \\
\hline Myrceugenia acutiflora (Kiaersk.) D.Legrand \& Kausel & $\mathrm{x}$ & - & - & - & - & 19996 \\
\hline Myrceugenia bracteosa (DC.) D.Legrand \& Kausel & $\mathrm{x}$ & $\mathrm{x}$ & - & - & $\mathrm{x}$ & 20001 \\
\hline Myrceugenia miersiana (Gardner) D.Legrand \& Kausel & - & $\mathrm{x}$ & - & $\mathrm{x}$ & $\mathrm{x}$ & 17341 \\
\hline Myrceugenia ovata (Hooker \& Arnot) O.Berg & - & - & $\mathrm{x}$ & $\mathrm{x}$ & $\mathrm{x}$ & 12930 \\
\hline Myrcia diaphana (O.Berg) N.Silveira & - & $\mathrm{x}$ & $\mathrm{x}$ & - & - & 17635 \\
\hline Myrcia eriopus DC. & - & $\mathrm{x}$ & - & - & $\mathrm{x}$ & 15350 \\
\hline Myrcia laruotteana Cambess. & $\mathrm{x}$ & $\mathrm{x}$ & - & $\mathrm{x}$ & $\mathrm{x}$ & 17337 \\
\hline Myrcia multiflora (Lam.) DC. & $\mathrm{x}$ & - & - & $\mathrm{x}$ & - & 16478 \\
\hline Myrcia obovata (O.Berg) Nied. & - & $\mathrm{x}$ & - & - & - & 17338 \\
\hline Myrcia pulchra Kiaersk. & $\mathrm{x}$ & $\mathrm{x}$ & $\mathrm{x}$ & $\mathrm{x}$ & - & 17334 \\
\hline Myrcia splendens (Swartz) DC. & - & $\mathrm{x}$ & $\mathrm{x}$ & $\mathrm{x}$ & $\mathrm{x}$ & 17336 \\
\hline Myrcia tomentosa (Aubl.) DC. & - & - & - & $\mathrm{x}$ & - & 16892 \\
\hline Myrciaria floribunda (West) O.Berg & - & $\mathrm{x}$ & - & - & - & 16279 \\
\hline Myrciaria tenella (DC.) O.Berg & $\mathrm{x}$ & $\mathrm{x}$ & - & $\mathrm{x}$ & - & 20000 \\
\hline Pimenta pseudocaryophyllus (Gomes) Landrum & - & - & - & $\mathrm{x}$ & - & 16895 \\
\hline Plinia cauliflora (Mart.) Kausel & - & $\mathrm{x}$ & - & - & - & 17339 \\
\hline Psidium rufum DC. & - & - & - & $\mathrm{x}$ & $\mathrm{x}$ & 16484 \\
\hline Siphoneugena densiflora O.Berg & - & $\mathrm{x}$ & $\mathrm{x}$ & - & - & 18964 \\
\hline Siphoneugena kuhlmannii Mattos & - & - & - & $\mathrm{x}$ & - & 18965 \\
\hline Siphoneugena widgreniana O.Berg & - & - & - & $\mathrm{X}$ & $\mathrm{X}$ & 17341 \\
\hline
\end{tabular}




\section{Famílias/Espécies}

NYCTAGINACEAE

Guapira graciliflora (Schmidt) Lundell

Guapira hirsuta (Choisy) Lundell

Guapira opposita (Vell.) Reitz

OCHNACEAE

Ouratea parviflora (DC.) Bail.

PICRAMNIACEAE

Picramnia glazioviana Engler

Picramnia parvifolia Engler

\section{PIPERACEAE}

Piperaduncum $\mathrm{L}$.

Piper amalago $\mathrm{L}$.

Pipercernuum Vell.

Piper crassinervium Kunth

Piper dilatatum L.C.Rich

\section{PODOCARPACEAE}

Podocarpus lambertii Klotzsch

Podocarpus sellowii Klotzsch

\section{PROTEACEAE}

Euplassa incana (Klotzsch) Johnston

Euplassa itatiae Sleumer

Euplassa legalis (Vell.) Johnston

Euplassa organensis (Gardner) Johnston

Roupala brasiliensis Klotzsch

Roupala montana Aubl.

Roupala rhombifolia Mart.

\section{QUIINACEAE}

Quiina glaziovii Engler

\section{ROSACEAE}

Prunus myrtifolia (L.) Urban

\section{RUBIACEAE}

Alibertia myrciifolia K.Schum.

Amaioua guianensis Aubl.

Bathysa australis (A.St.-Hil.) Benth. \& Hook.f.

Chomelia brasiliana A.Rich.

Chomelia sericea Müll.Arg.

Coutarea hexandra (Jacq.) K.Schum.

Faramea cyanea Müll.Arg.

Guettarda uruguensis Cham. \& Schltdl.

Hillia parasitica Jacq.

Ixora warmingii Müll.Arg.

Psychotria hastisepala Müll.Arg.

Psychotria suterella Müll.Arg.

Psychotria vellosiana Benth.

Rudgea jasminoides (Cham.) Müll.Arg.

Rudgea recurva Müll.Arg.
Bmi-1 Bmi-2 Bmi-3 Aiu Vma Registro

3105

15133

15375

20002

20003

15110

15371

20004

17344

17345

17346

17347

15369

12584

16288

15127

17348

16571

10899

15368

$\begin{array}{lllllll}\text { X } & \text { X } & \text { X } & \text { X } & \text { X } & 16574\end{array}$

$\begin{array}{llllll}\mathrm{x} & - & - & - & \mathrm{X} & 20005\end{array}$

$\begin{array}{llllll}- & \mathrm{X} & \mathrm{X} & \mathrm{X} & - & 15364\end{array}$

$\begin{array}{llllll}- & \mathrm{X} & - & \mathrm{X} & \mathrm{X} & 17352\end{array}$

$\begin{array}{lllllll}\mathrm{x} & - & - & - & - & - & -\end{array}$

$\begin{array}{llllll}- & - & - & \mathrm{x} & - & 12559\end{array}$

\begin{tabular}{llllll}
\hline & - & - & $\mathrm{X}$ & & 12559 \\
\hline
\end{tabular}

\begin{tabular}{llllll}
\hline & - & - & $\mathrm{x}$ & - & 16580
\end{tabular}

$\begin{array}{llllll}- & - & - & \mathrm{x} & - & 13219\end{array}$

$\begin{array}{llllll}- & \mathrm{X} & - & - & - & 16293\end{array}$

$\begin{array}{llllll}- & - & - & \mathrm{x} & - & 16583\end{array}$

$\begin{array}{lllllll}- & - & - & \mathrm{x} & - & 16587\end{array}$

$\begin{array}{llllll}- & \mathrm{x} & \mathrm{x} & - & \mathrm{x} & 20006\end{array}$

$\begin{array}{llllll}- & \mathrm{X} & \mathrm{X} & \mathrm{x} & \mathrm{x} & 10235\end{array}$

$\begin{array}{llllll}- & \mathrm{X} & - & \mathrm{X} & \mathrm{X} & 15354\end{array}$

$\begin{array}{llllll}- & \mathrm{X} & - & - & \mathrm{X} & 15462\end{array}$ 
Famílias/Espécies

RUTACEAE

Dictyoloma vandellianum A.Juss.

Esenbeckia grandiflora Mart.

Pilocarpus pauciflorus A.St.-Hil.

Zanthoxylum caribaeum Lam.

Zanthoxylum rhoifolium Lam.

\section{SABIACEAE}

Meliosma brasiliensis Urban

Meliosma itatiaiae Urban

Meliosma sellowii Urban

Meliosma sinuata Urban

\section{SALICACEAE}

Casearia arborea (L.C.Rich.) Urban

Casearia decandra Jacq.

Casearia grandiflora Cambess.

Casearia lasiophylla Eichler

Casearia mariquitensis Kunth

Casearia obliqua Sprengel

Casearia pauciflora Cambess.

Casearia rufescens Cambess.

Casearia rupestris Eichler

Casearia sylvestris Swartz

Casearia ulmifolia Vahl

Xylosma prockia (Turcz.) Turcz.

Xylosma venosa N.E.Brown

\section{SAPINDACEAE}

Allophylus edulis (A.St.-Hil.) Radlk.

Allophylus guaraniticus (A.St.-Hil.) Radlk.

Allophylus semidentatus (Miq.) Radlk.

Cupania ludowigii Somner \& Ferruci

Cupania racemosa (Vell.) Radlk.

Cupania vernalis Cambess.

Cupania zanthoxyloides Cambess.

Diatenopteryx sorbifolia Radlk.

Matayba guianensis Aubl.

Toulicia laevigata Radlk.

\section{SAPOTACEAE}

Chrysophyllum gonocarpum (Mart. \& Eichler) Engler

Chrysophyllum marginatum (Hooker \& Arnot) Radlk.

Micropholis crassipedicelata (Mart. \& Eichler) Pierre

Micropholis gardneriana (A.DC.) Pierre

Pouteria caimito (Ruiz \& Pav.) Radlk.

Pouteria guianensis Aubl.

\section{SIPARUNACEAE}

Siparuna cujabana (Mart.) A.DC.

Siparuna guianensis Aubl.

Bmi-1 Bmi-2 Bmi-3 Aiu Vma Registro

$\begin{array}{llllll}- & - & - & \mathrm{X} & \mathrm{X} & 16297 \\ - & \mathrm{X} & \mathrm{X} & - & - & 20007 \\ - & \mathrm{X} & - & - & - & 17358 \\ - & - & - & \mathrm{X} & - & 15119 \\ - & \mathrm{X} & - & \mathrm{X} & - & 15472 \\ & & & & & \\ - & \mathrm{X} & \mathrm{X} & - & - & 20008 \\ - & - & - & - & \mathrm{X} & - \\ - & \mathrm{X} & - & - & \mathrm{X} & 15476 \\ - & \mathrm{X} & - & - & - & 13542\end{array}$

\begin{tabular}{|c|c|c|c|c|c|}
\hline- & $\mathrm{X}$ & - & $\mathrm{X}$ & - & 17286 \\
\hline- & $\mathrm{X}$ & - & $\mathrm{X}$ & $\mathrm{X}$ & 17287 \\
\hline- & - & - & - & $\mathrm{X}$ & 17698 \\
\hline- & - & - & $\mathrm{X}$ & $\mathrm{X}$ & 16447 \\
\hline- & $\mathrm{X}$ & - & $\mathrm{X}$ & - & 17107 \\
\hline- & $\mathrm{X}$ & - & $\mathrm{X}$ & $\mathrm{X}$ & 19517 \\
\hline- & $\mathrm{X}$ & - & - & - & 17288 \\
\hline- & - & - & - & $X$ & - \\
\hline- & - & $\mathrm{X}$ & - & - & 20009 \\
\hline $\mathrm{X}$ & - & - & $\mathrm{X}$ & $X$ & 17658 \\
\hline- & - & - & $\mathrm{X}$ & - & 16040 \\
\hline $\mathrm{X}$ & - & $\mathrm{X}$ & - & - & 17658 \\
\hline- & $\mathrm{X}$ & - & $\mathrm{X}$ & - & 17289 \\
\hline $\mathrm{X}$ & $\mathrm{X}$ & - & - & - & 20010 \\
\hline $\mathrm{X}$ & - & - & - & - & - \\
\hline- & - & - & $\mathrm{X}$ & - & 19148 \\
\hline $\mathrm{X}$ & $\mathrm{X}$ & - & $\mathrm{X}$ & - & 20011 \\
\hline- & - & - & - & $\mathrm{X}$ & 15446 \\
\hline- & $\mathrm{X}$ & - & $\mathrm{X}$ & - & 17210 \\
\hline $\mathrm{X}$ & $\mathrm{X}$ & $\mathrm{X}$ & - & - & 15447 \\
\hline- & - & - & $\mathrm{X}$ & - & 17211 \\
\hline $\mathrm{X}$ & $\mathrm{X}$ & - & $\mathrm{X}$ & $\mathrm{X}$ & 17212 \\
\hline- & $\mathrm{X}$ & - & - & - & 17361 \\
\hline- & $\mathrm{X}$ & - & - & - & 17213 \\
\hline- & - & - & $\mathrm{X}$ & $\mathrm{X}$ & 16927 \\
\hline- & - & - & - & $\mathrm{X}$ & - \\
\hline- & - & - & - & $\mathrm{X}$ & 15111 \\
\hline- & $\mathrm{X}$ & - & - & $\mathrm{X}$ & 17362 \\
\hline- & $\mathrm{X}$ & - & - & - & 17363 \\
\hline- & - & - & $X$ & - & 1316 \\
\hline- & - & - & $\mathrm{X}$ & - & 19375 \\
\hline
\end{tabular}




\section{Famílias/Espécies}

SOLANACEAE

Brugmansia suaveolens (Willd.) Bercht. \& J.Presl.

Cestrum corymbosum Schltdl.

Cestrum schlechtendalii G.Don

Dyssochroma viridiflora Miers

Solanum bullatum Vell.

Solanum cinnamomeum Sendt.

Solanum granulosoleprosum Dunal

Solanum itatiaiae Glaziou

Solanum lepidotum Dunal

Solanum leucodendron Sendt.

Solanum pseudoquina A.St.-Hil.

Solanum swartzianum Roem. \& Schult.

\section{STYRACACEAE}

Pamphilia aurea Mart.

\section{SYMPLOCACEAE}

Symplocos celastrinea Mart.

Symplocos insignis Brand

\section{THEACEAE}

Gordonia fruticosa (Schrader) H.Keng.

\section{THEOPHRASTACEAE}

Clavija macrophylla (Link) Miq.

\section{THYMELAEACEAE}

Daphnopsis coriacea Taub.

Daphnopsis fasciculata (Meisn.) Nevling

Daphnopsis martii Meisn.

Daphnopsis sellowiana Taub.

\section{URTICACEAE}

Cecropia glaziovii Snethl.

Cecropia hololeuca Miq.

Cecropia pachystachya Trécul

Coussapoa microcarpa (Schott) Rizz.

Urera caracasana (Jacq.) Griseb.

\section{VERBENACEAE}

Duranta vestita Cham.

\section{VOCHYSIACEAE}

Qualea cordata (Mart.) Sprengel Qualea dichotoma (Mart.) Warm. Vochysia bifalcata Warm.

Vochysia glazioviana Warm.

Vochysia laurifolia Warm.

Vochysia magnifica Warm.

Vochysia rectiflora Warm.

Vochysia schwackeana Warm.

Vochysia tucanorum Mart.

\section{WINTERACEAE}

Drimys brasiliensis Miers
Bmi-1 Bmi-2 Bmi-3 Aiu Vma

$\begin{array}{cccccc}- & \mathrm{x} & - & - & - & 17364 \\ - & \mathrm{x} & - & - & - & 17365 \\ - & \mathrm{x} & \mathrm{x} & \mathrm{x} & \mathrm{x} & 17366 \\ - & \mathrm{x} & - & - & - & 17367 \\ - & \mathrm{x} & - & \mathrm{x} & - & 17393 \\ - & \mathrm{x} & \mathrm{x} & - & - & 20012 \\ \mathrm{x} & \mathrm{x} & \mathrm{x} & \mathrm{x} & \mathrm{x} & 15478 \\ - & - & - & - & \mathrm{x} & - \\ \mathrm{x} & \mathrm{x} & \mathrm{x} & - & - & 20013 \\ - & \mathrm{x} & - & - & \mathrm{x} & 17218 \\ - & \mathrm{x} & \mathrm{x} & \mathrm{x} & \mathrm{x} & 17369 \\ - & \mathrm{x} & \mathrm{x} & - & - & 17370 \\ & & & & & \\ - & \mathrm{x} & - & - & - & 17371\end{array}$

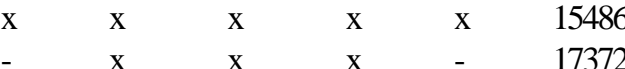

15486

20014

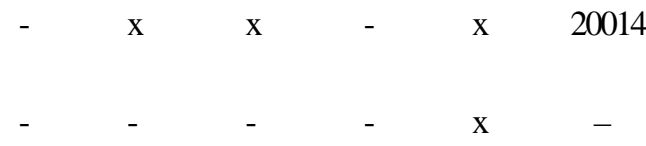

$\mathrm{X}$

$\mathrm{X}$

$\mathrm{X}$

20016

20114

$\begin{array}{cccccc}- & \mathrm{x} & - & \mathrm{x} & \mathrm{x} & 16403 \\ - & \mathrm{x} & - & \mathrm{x} & \mathrm{x} & 10290 \\ - & - & - & \mathrm{x} & - & 16404 \\ - & \mathrm{x} & - & \mathrm{x} & - & 17082 \\ - & - & - & \mathrm{x} & - & 17769\end{array}$

20018

$\begin{array}{cccccc}- & - & - & \mathrm{x} & - & 16303 \\ - & - & - & \mathrm{x} & - & 19552 \\ - & - & - & - & \mathrm{x} & 17224 \\ - & - & - & - & \mathrm{x} & - \\ - & - & - & - & \mathrm{x} & - \\ - & \mathrm{x} & - & \mathrm{x} & - & 17376 \\ - & - & - & - & \mathrm{x} & - \\ - & - & - & - & \mathrm{x} & - \\ - & - & \mathrm{x} & \mathrm{x} & - & 17227\end{array}$ 


\section{Análise florística}

Segundo Gentry (1995), a composição e riqueza de espécies lenhosas nas florestas tropicais está relacionada a cinco gradientes principais: o intercontinental, o latitudinal, o de precipitação, o edáfico e o altitudinal. Os dois últimos provavelmente explicam boa parte da diferenciação florística entre os seis remanescentes florestais do maciço do Itatiaia que emerge do dendrograma gerado pela análise de agrupamentos (Fig. 2, Tabela 3). A área Bmi-1 mostrou-se como a mais distinta, separando-se no nível mais baixo de similaridade com as demais áreas $\left(\mathrm{I}_{\mathrm{J}}=0,08\right.$ a 0,16 ), o que sugere que o fator edáfico foi preponderante, pois este é o único remanescente de floresta ombrófila aluvial entre as fisionomias representadas. Conforme discutido acima, este padrão reforça o critério do IBGE (1997) de classificação das florestas aluviais como uma fisionomia bem particular, independente do piso altitudinal. A segunda área a se destacar pela composição foi Itt, que também apresentou valores muito baixos de similaridade florística com as demais áreas (coincidentemente, $I_{J}=0,08$ a 0,16). Segue-se a área de Vma, que é também a única área de floresta ombrófila mista. Nestes dois casos, é importante salientar que, ao contrário dos demais remanescentes, Itt e Vma encontramse na vertente oceânica do maciço do Itatiaia e bacia do rio Paraíba, enquanto os demais remanescentes (Bmi-1/2/3 e Aiu) encontram- se na vertente continental e bacia do rio Grande. A exposição de vertentes em cadeias de montanha pode ter um papel fundamental na definição de padrões de precipitação e temperatura e, por conseguinte, na distribuição de espécies de plantas (Hugget 1995). No complexo da Mantiqueira, em geral, as chuvas tem uma distribuição mais estacional nas vertentes continentais que nas oceânicas (Oliveira-Filho \& Fontes 2000). Contudo, esta explicação não pôde ser aplicada ao presente caso, pois os dados climáticos não corroboram esta tendência: as estações secas com menos chuva se verificaram em Itt e Aiu, com exposição oceânica e continental, respectivamente, e o mesmo ocorreu com as estações secas com mais chuva, em Vma e

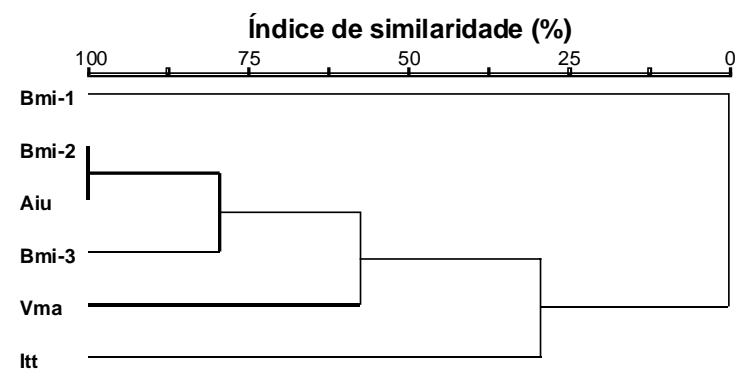

Figura 2 - Dendrograma de similaridade produzido por análise de agrupamento da composição de espécioes de seis áreas de floresta ombrófila montana no maciço do Itatiaia nos estados de Minas Gerais e Rio de Janeiro. Bmi-1/2/3 = Bocaina de Minas 1/2/3, Aiu = Aiuruoca; $\mathrm{Vma}=$ Visconde de Mauá; Itt = Itatiaia.

Tabela 3 - Matriz florística das seis áreas de floresta ombrófila montana da região do maciço do Itatiaia mostrando o número de espécies em comum entre as áreas na metade superior direita e os índices de similaridade de Jaccard na metade inferior esquerda. Bmi-1/2/3 = Bocaina de Minas 1/2/3, Aiu = Aiuruoca; Vma = Visconde de Mauá; Itt = Itatiaia.

\begin{tabular}{lccccccc}
\hline & Bmi1 & Bmi2 & Bmi3 & Aiu & Itt & Vma & Totais \\
\hline Bmi1 & - & 41 & 21 & 38 & 15 & 26 & 81 \\
Bmi2 & 0,16 & - & 85 & 119 & 45 & 85 & 218 \\
Bmi3 & 0,12 & 0,34 & - & 59 & 24 & 54 & 119 \\
Aiu & 0,14 & 0,36 & 0,20 & - & 44 & 79 & 228 \\
Itt & 0,08 & 0,15 & 0,11 & 0,14 & - & 44 & 127 \\
Vma & 0,11 & 0,26 & 0,21 & 0,23 & 0,16 & - & 190 \\
\hline
\end{tabular}


Bmi. É possível que fatores históricos e geográficos, como as flutuações climáticas e isolamento entre bacias pelas cadeias montanhosas, exerçam uma influência mais forte que o próprio clima atual das áreas.

As três áreas de maior similaridade florística entre si $\left(I_{J}=0,20\right.$ a 0,36$)$ são, precisamente, as fisionomias de floresta ombrófila montana da vertente continental. A maior semelhança foi verificada entre Bmi-2 e Aiu $\left(I_{J}=0,36\right.$ e 119 espécies em comum), apesar da distância entre elas, cerca de $45 \mathrm{~km}$, ser bem superior à que separa Bmi-2 e Bmi-3, apenas $5 \mathrm{~km}$. A maior dissimilaridade entre estas duas áreas e Bmi-3 deve-se provavelmente ao fato de se tratar de uma floresta em estágio inicial de sucessão, ao contrário das outras duas, que são bem mais maduras. No entanto, isto só é claro na distinção entre Aiu e Bmi-3, pois a similaridade florística entre Bmi-2 e Bmi-3 também pode ser considerada alta $\left(I_{j}>0,30\right)$. Isto se deve provavelmente ao fato de que estas áreas encontram-se geograficamente bem próximas e sob condições topográficas e edáficas bem parecidas, sendo o estágio sucessional o único fator diferenciador evidente entre elas.

\section{Conclusões}

A flora arbórea das florestas do maciço do Itatiaia pode ser considerada como uma das mais ricas entre as florestas atlânticas de montanha do sudeste do Brasil. Muito desta diversidade deve-seà pronunciadaheterogeneidade florística entre as florestas da região. Entre os fatores que provavelmenteinfluenciam mais fortemente esta diferenciação florística estão a exposição de vertentes, o regime de drenagem dos solos e o estágio sucessional.

\section{REFERÊNCIAS Bibliográficas}

Almeida, D. S. 1996. Florística e estrutura de um fragmento de Floresta Atlântica, no município de Juiz de Fora, Minas Gerais. Dissertação de Mestrado, Viçosa, Universidade Federal de Viçosa, 91p.
APG. 2003. An update of the Angiosperm Phylogeny Group classification for the orders and families of flowering plants: APG II. Botanical Journal of the Linnean Society 141: 399-436.

Baitello, J. B. \& Aguiar, O. T. 1982. Flora arbórea da Serra da Cantareira. Anais do I Congresso Nacional sobre Essências Nativas. Silvicultura em São Paulo 16A: 582-646.

Baitello, J. B.; Aguiar, O. T.; Rocha, F. T.; Pastore, J. A. \& Esteves, R. 1992. Florística e fitossociologia do estrato arbóreo de um trecho da Serra da Cantareira (Núcleo Pinheirinho), SP. Anais do II Congresso Nacional sobre Essências Nativas. Revista do Instituto Florestal de São Paulo 4: 291-297.

Botrel, R. T.; Oliveira-Filho, A. T.; Rodrigues, L. A. \& Curi, N. 2002. Composição florística e estrutura da comunidade arbórea de um fragmento de floresta estacional semidecidual em Ingaí, MG, e a influência de variáveis ambientais na distribuição das espécies. Revista Brasileira de Botânica 25: 195-213.

Brower, J. E. \& Zar, J. H. 1984. Field and laboratory methods for general ecology. Dubuque, W. M. C. Brow, 84 p.

Câmara, I. G. 2003. Brief history of conservation in the Atlantic forest. In: Galindo-Leal, C. \& Câmara, I. G. (eds.). The Atlantic Forest of South America. Washington, Center for Applied Biodiversity Science, pp. 31-42.

Carvalho, D. A.; Oliveira-Filho, A. T.; van den Berg, E.; Fontes, M. A. L.; Vilela, E. A.; Marques, J. J. G. S. M. \& Carvalho, W. A. C. 2005. Variações florísticas e estruturais do componente arbóreo de uma floresta ombrófila alto-montana às margens do Rio Grande, Bocaina de Minas, MG, Brasil. Acta Botanica Brasilica 19: 91-109.

Castro, A. G. 2001. Levantamento de espécies em um trecho de Floresta Atlântica na Estação Ecológica de Bananal, serra da 
Bocaina, Bananal, SP. Dissertação de Mestrado, Universidade Federal Rural do Rio de Janeiro, Rio de Janeiro.

Collinge, S. K. 1996. Ecological consequences of habitat fragmentation: implications of landscape architecture and planning. Landscape and Urban Planning, v.36, p. 59-77.

Dalanesi, P. E.; Oliveira-Filho, A. T. \& Fontes, M. A. L. 2004. Flora e estrutura do componente arbóreo da floresta do Parque Ecológico Quedas do Rio Bonito, Lavras, MG, e correlações entre a distribuição das espécies e variáveis ambientais. Acta Botanica Brasilica 18:737-757.

Fernandes, F. A. B. 2003. Estudo de gradientes vegetacionais em umafloresta semidecídua altimontana no planalto de Poços de Caldas, MG. Dissertação de Mestrado, Lavras, Universidade Federal de Lavras, $157 \mathrm{p}$.

Fontes, M. A. L. 1997. Análise da composição florística das florestas nebulares do Parque Estadual de Ibitipoca. Dissertação de Mestrado, Lavras, Universidade Federal de Lavras, 50p.

França, G. S. \& Stehmann, J. R. 2004. Composição florística e estrutura do componente arbóreo de uma floresta altimontanano município de Camanducaia, Minas Gerais, Brasil. Revista Brasileira de Botânica 27: 19-30.

Galindo-Leal, C. \& Câmara, I. G. 2003. Atlantic Foresthotspot status: an overview. In: Galindo-Leal, C. \& Câmara, I. G. (eds.). The Atlantic Forest of South America. Washington, Center for Applied Biodiversity Science, p. 3-11.

Galindo-Leal, C.; Jacobsen, T. R.; Langhammer, P. F. \& Olivieri, S. 2003. State of the hotspots: the dynamics of biodiversity loss. In: Galindo-Leal, C. \& Câmara, I. G. (eds.). The Atlantic Forest of South America. Washington, Center for Applied Biodiversity Science, p. 12-23.
Gentry, A. H. 1995. Patterns of diversity and floristic composition in neotropical montane forests. Pp.103-126. In: Churchill, S. P.; Balslev, H.; Forero, E. \& Luteyn, J. L. (eds.). Biodiversity and Conservation of Neotropical Montane Forests: Proceedings of Neotropical Montane Forest Biodiversity and Conservation Symposium. The New York Botanical Garden, New York.

Grombone, M. T.; Bernacci, L. C.; MeiraNeto, J. A.; Tamashiro, J. Y. \& LeitãoFilho, H. F. 1990. Estrutura fitossociológica da floresta semidecídua de altitude do Parque Municipal da Grota Funda (Atibaia-Estado de São Paulo). Acta Botanica Brasílica 4: 47-64.

Guedes-Bruni, R. R. 1998. Composição, estrutura e similaridade florística de dossel em seis unidades fisionômicas de mata atlântica no Rio de Janeiro. Tese de Doutorado, São Paulo, Universidade de São Paulo, 347 p.

Guilherme, F. A. G.; Oliveira-Filho, A. T.; Appolinário, V. \& Bearzoti, E. 2004. Effects of flooding regimes and woody bamboos on tree community dynamics in a section of tropical semideciduous forest in South-Eastern Brazil. PlantEcology 174: 19-36.

Heltshe, J. F. \& Forrester, N. E. 1983. Estimating species richness using the jackknife procedure. Biometrics 39: 1-12.

Hugget, R. J. 1995. Geoecology, an evolution ary approach. Routledge, London.

Ivanauskas, N. M. \& Rodrigues, R. R. 2000. Similaridade florística entre áreas de Floresta Atlântica no estado de São Paulo. Brazilian Journal of Ecology 4: 71-81.

Kent, M. \& Coker, P. 1992. Vegetation description and analysis, a practical approach. Belhaven Press, London, 215p.

Lieberman, M.; Lieberman, D.; Peralta, R. \& Hartshorn, G. S. 1995. Canopy closure 
and distribution of tropical forest tree species at La selva, Costa Rica. Journal of Tropical Ecology 11: 161-178.

Lieberman, D.; Lieberman, M.; Peralta, R. \& Hartshorn, G. S. 1996. Tropical forest structure and composition on a large-scale altitudinal gradient in Costa Rica. Journal of Ecology 84: 137-152.

Lima, M. P. M. \& Guedes-Bruni, R. R. 1994. Reserva ecológica de Macaé de Cima Nova Friburgo - RJ: aspectos florísticos das espécies vasculares. Jardim Botânico do Rio de Janeiro, Rio de Janeiro.

Mantovani, W.; Rossi, L.; Romaniuc-Neto, S.; Catharino, E. L. M. \& Cordeiro, I. 1990. A vegetação na Serra do Mar em Salesópolis, SP. In: Simpósio de Ecossistemas da Costa Sul e Sudeste Brasileira, 2, Anais... São Paulo: ACIESP, pp. 348384.

McCune, B. \& Mefford, M. J. 1999. PC-ORD version 4.0., multivariate analysis of ecological data, Users guide. Glaneden Beach, MjM Software Design, 148p.

Meguro, M.; Pirani, J. R.; Mello-Silva, R. \& Giulietti, A. M. 1996. Caracterização florística e estrutural de matas ripárias e capões de altitude na Serra do Cipó, Minas Gerais. Boletim de Botânica da Universidade de São Paulo 15: 13-29.

Meira Neto, J. A.; Bernacci, L. C.; Grombone, M. T.; Tamashiro, J. Y. \& Leitão-Filho, H. F. 1989. Composição florística da floresta semidecídua de altitude do Parque Municipal da Grota Funda (Atibaia, estado de São Paulo). Acta Botanica Brasilica 3: 51-74.

Moreno, M. R.; Nascimento, M. T. \& Kurtz, B. 2003. Estrutura e composição florística do estrato arbóreo em duas zonas altitudinais na mata atlântica de encosta da região do Imbé, RJ. Acta Botanica Brasilica 17: 325-486.

Oliveira-Filho, A. T.; Carvalho, D. A.; Fontes, M. A. L.; van den Berg, E.; Curi, N. \& Carvalho, W. A. C. 2004. Variações estruturais do compartimento arbóreo de uma floresta semidecídua alto-montana na chapada das Perdizes, Carrancas, MG. Revista Brasileira de Botânica 27(2): 291309.

Oliveira-Filho, A. T. \& Fontes M.A.L. 2000. Patterns of floristic differentiation among Atlantic forests in south-eastern Brazil, and the influence of climate. Biotropica 32(4b): 793-810.

Oliveira-Filho, A. T. \& Machado, J. N. M. 1993. Composição florística de uma floresta semidecídua montana, na Serra de São José, Tiradentes, Minas Gerais. Acta Botanica Brasilica 7: 71-88.

Oliveira-Filho, A. T.; Vilela, E. A.; Gavilanes, M. L. \& Carvalho, D. A. 1994. Comparison of the woody flora and soils of six areas of montane semideciduos forest in southern Minas Gerais, Brazil. Edinburgh Journal of Botany 5: 355-389.

Palmer M. W. 1991. Estimating species richness: The second-order jackknife reconsidered. Ecology 72: 1512-1513.

Pendry, C. A. \& Proctor, J. 1996. The causes of altitudinal zonation of rain forests on Bukit Belalong, Brunei. Journal of Ecology 84: 407-418.

Pereira, J. A. A. 2003. Efeitos dos impactos ambientais e da heterogeneidade ambiental sobre a diversidade e estrutura da comunidade arbórea de 20 fragmentos de florestas semidecíduas da região do Alto Rio Grande, Minas Gerais. Tese de doutorado, Universidade Federal de Minas Gerais, Belo Horizonte.

Pirani, J. R.; Giulietti, A.; Mello-Silva, R. \& Meguro, M. 1994. Checklist and patterns of geographic distribution of the vegetation of Serra do Ambrósio, Minas Gerais, Brazil. Revista Brasileira de Botânica 17(2): 133-147.

Proctor, J.; Lee, Y. F.; Langley, A. M.; Munro, W. R. C. \& Nelson, T. 1988. Ecological studies on Gunung Silan, a small ultrabasic mountain in Sabah, Malaysia. I. 
Environment, Forest structure and floristics. Journal of Ecology 76: 320-340.

Robim, M. J.; Pastore, J. A.; Aguiar, O. T. \& Baitello, J. B. 1990. Flora arbóreo arbustiva e herbácea do Parque Estadual de Campos do Jordão (SP). Revista do Instituto Florestal de São Pauo 2: 31-53.

Rodrigues, R. R. \& Nave, A. G. 2001. Heterogeneidade florísticas das matas ciliares. In: Rodrigues, R. R.; Leitão Filho, H. F. Matas ciliares: conservação e restauração. São Paulo: EDUSP, pp. 45-71.

Rodrigues, R. R.; Morellato, L. P. C.; Joly, C. A. \& Leitão-Filho, H. F. 1989. Estudo florístico e fitossociológico em um gradiente altitudinal de mata estacional mesófila semidecídua na Serra do Japi, Jundiaí, SP. Revista Brasileira de Botânica 12(1/2): 71-84.

Salis, S. M.; Shepherd, G. J. \& Joly, C. A. 1995. Floristic comparison of mesophytic semi-deciduous forests of the interior of the state of São Paulo, southeast Brazil. Vegetatio 119(2): 155-164.

Scudeller, V. V.; Martins, F. R. \& Shepherd, G. J. 2001. Distribution and abundance of arboreal species in the Atlantic Ombrophilous Dense Forest in Southeastern Brazil. PlantEcology 152: 185-199.

Veloso, H. P.; Rangel Filho, A. L. R. \& Lima, J. C. A. 1991. Classificação da vegetação brasileira adaptada a um sistema universal. Instituto Brasileiro de Geografia e Estatística, Rio de Janeiro.

Viana, V. M.; Tabanez, A. J. A. 1996. Biology and conservation of forest fragments in Brazilian atlantic moist florest. In: Schellas, J.; Greenberg, R. (ed.). Forest patches in tropical landscapes. Washington: Island Press, pp. 151-167.

Webster, G. L. 1995. The panorama of Neotropical Cloud Forests. In: Churchill, S. P.; Balslev, H.; Forero, E. \& Luteyn, J. L. (eds.). Biodiversity and Conservation of Neotropical Montane Forests: Proceedings of Neotropical Montane Forest Biodiversity and Conservation Symposium. The New York Botanical Garden, New York. Pp. 53-77.

Whitmore, T. C. 1990. An introduction to tropical rain forests. Oxford University Press, Oxford. 
